\title{
Pore Structure and Fluid Uptake of the Springer/Goddard Shale Formation in Southeastern Oklahoma, USA
}

\author{
Qinhong Hu $\mathbb{D}^{1,2,3}$ Wen Zhou, ${ }^{4}$ Paul Huggins, ${ }^{3}$ and Wenling Chen ${ }^{4}$ \\ ${ }^{1}$ School of Geosciences, China University of Petroleum (East China), Qingdao 266580, China \\ ${ }^{2}$ Laboratory for Marine Mineral Resources, Qingdao National Laboratory for Marine Science and Technology, \\ Qingdao 266071, China \\ ${ }^{3}$ Department of Earth and Environmental Sciences, The University of Texas at Arlington, Arlington, TX 76019, USA \\ ${ }^{4}$ State Key Laboratory of Oil and Gas Reservoir Geology and Exploitation, Chengdu University of Technology, \\ Chengdu 910059, China
}

Correspondence should be addressed to Qinhong Hu; maxhu@uta.edu

Received 3 November 2017; Revised 24 February 2018; Accepted 20 May 2018; Published 11 July 2018

Academic Editor: Paolo Fulignati

Copyright (c) 2018 Qinhong Hu et al. This is an open access article distributed under the Creative Commons Attribution License, which permits unrestricted use, distribution, and reproduction in any medium, provided the original work is properly cited.

\begin{abstract}
Hosting an emerging play of the Springer/Goddard shale, the South Central Oklahoma Oil Province (SCOOP), is also the main production field for the underlying Woodford Formation. Understanding the reservoir quality of the Chesterian-age Goddard shale, currently little has been achieved, is vital to sustainable hydrocarbon production and exploration. Using polar (DI water and/or API brine) and nonpolar (n-decane) fluids to probe hydrophilic and hydrophobic pore networks, the purpose of this study is to examine wettability, pore connectivity, fluid imbibition, and tracer migration of the Springer shale. To achieve this, we collected core samples from two wells located at the heart of the play and performed mercury injection capillary pressure, wettability, fluid imbibition, and vapor absorption tests. Results from these studies show that the Springer shale has a stronger affinity to oil (n-decane in this study), compared to DI water and API brine. With porosity values averaging at $6.32 \pm 0.75 \%$ and permeability of $20.0 \pm 6.52 \mathrm{nD}$, the majority of pore-throat sizes for the Springer shale are $5-50 \mathrm{~nm}$. The utility of wettability tracers of different molecular sizes helps tease out the intertwined relationship of pore-throat sizes, connectivity, and associated wettability of shale. The imbibition results suggest a molecular entanglement effect at the scale of $0.5 \mathrm{~nm}$, even for the tracer penetration of a wetting fluid of $n$-decane. A petrophysical analysis of the Springer shale presented in this work is beneficial to further understand the pore structure and fluid movement within the shale to facilitate increased production and accurate economic evaluations.
\end{abstract}

\section{Introduction}

Since 1905, Oklahoma has been producing gas and oil originating from its multiple shale resource plays, with the Woodford shale the most important one, from four geological provinces (Anadarko Basin, Ardmore Basin, Arkoma Basin, and Cherokee Platform) [1]. Since 2004, well completions from brittle, silica-rich Woodford shale have expanded from gas production in Arkoma Basin to a production of gas, condensate, and oil in all four provinces, including the South Central Oklahoma Oil Province (SCOOP) area initiated in 2012 (Figure 1). There were a total of 4389 Woodford-only well completions during 2004-2016, with $91 \%$ being horizontal/directional wells and 1204 oil wells [2].

Located within the already producing SCOOP area in the southeastern Anadarko Basin, the lower Springer/Goddard shale $[3,4]$ has been the newest shale resource play in Oklahoma since 2013 and boasts 5.1 billion barrels of liquid hydrocarbons and 135 trillion cubic feet of recoverable gas $[5,6]$. But only 2.3 billion barrels of liquids and 65.5 trillion cubic feet of gas have been recovered, leaving more than double that is still recoverable as of 1995 [7]. There were 57 horizontal Springer shale well completions in Carter, Garvin, Grady, and Stephens counties during 2013-2016, 

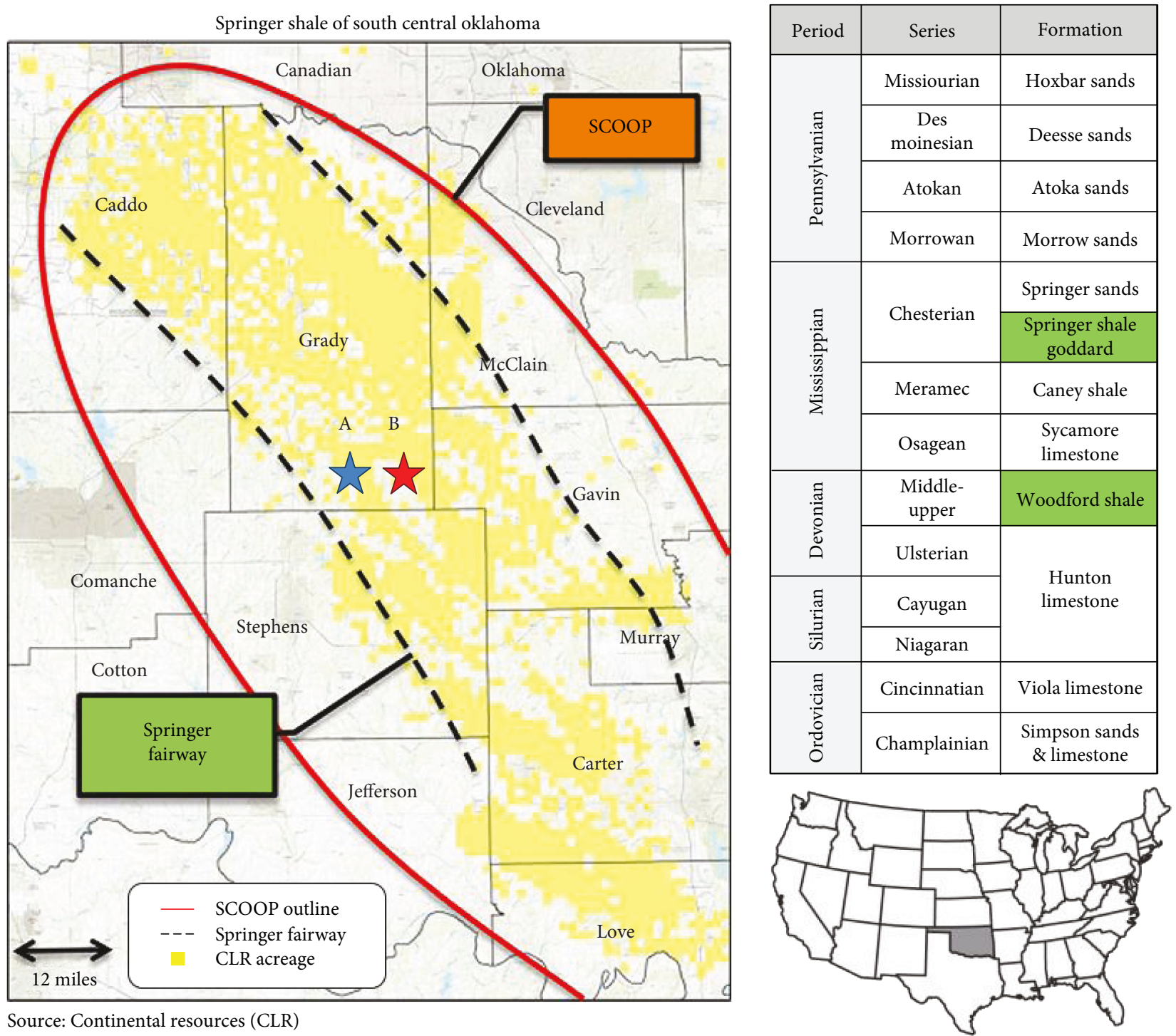

FIGURE 1: Location map and stratigraphic column of SCOOP and Springer Fairway (modified from [1, 9]); also shown are two sampling wells.

with Continental Resources holding the largest acreage. As a "niche play" to be stacked with the Woodford shale to cost-effectively utilize existing infrastructure, the Springer shale ranks between 30th and 35th in terms of production values, among a total of 200 shale plays in North America [8]. Single-well breakeven price for the Springer shale is $\$ 40 /$ barrel, compared to $\$ 45$ for Eagle Ford and \$50 for Bakken [9].

Along with the Springer, the current producing major formations include the Caney, Sycamore, and Woodford (Figure 1), each with their own petrophysical properties that allow for the exploitation of hydrocarbons [10]. This study evaluates the petrophysical attributes, with respect to pore structure and fluid movement, of the Springer shale for more effective exploration and production. While such studies have been performed for other major shale plays [11-13], the literature survey indicates minimal results for the Springer shale. Located at depths of $3353-4267 \mathrm{~m}$, the Springer shale has a thickness of $18-36 \mathrm{~m}$, total organic content (TOC) of 3-4\%, and porosity of 3-9\% [14]. As summarized in Cardott [2], a total of 36 Springer shale samples in the Anadarko Basin contain type III kerogen with an average TOC value of $1.6 \mathrm{wt} \%$ (ranging from $<1$ to $4.31 \mathrm{wt} \%$ ), while another study reported type II kerogen and $<1$ to 7.7 wt $\%$ TOC.

\section{Materials and Methods}

2.1. Geologic Setting and Depositional Environment. The Springer shale lies on the southeastern edge of the Anadarko Basin, which subsided during the Paleozoic, and has faulting associated with the Wichita orogeny that lasted from the early Pennsylvanian until the end of the Permian $[5,15]$. It is bound to the east by the Nemaha Uplift, to the southeast by the Arbuckle Mountains and Ardmore Basin, and to the south by the Wichita Mountains and Amarillo Uplift [3]. The basin is bounded to the west by the Cimarron and Las 
Animas Arches, to the north by the Central Kansas Uplift, and the Pratt Anticline to the northeast [7].

The Anadarko Basin covers about $150,220 \mathrm{~km}^{2}$ and is the deepest basin in the cratonic U.S. [5]. The stratigraphy in the area ranges from the Cambrian to the Permian and reaches more than $11.5 \mathrm{~km}$ in the deepest parts of the basin [16]. There are also Mesozoic and Cenozoic sedimentary rocks toward the northwest overlying the Paleozoic strata [5]. Carbonates make up the older parts of the basin that start at the Cambrian and continue intermittently through the Mississippian, while sandstones and shales make up the younger parts of the basin [5]. The volume of sandstones increases towards the southern part of the basin due to the synsedimentary faulting producing the Wichita Mountain Belt.

The Springer Group is of Mississippian and Pennsylvanian age and consists of sand bodies with interbedded shales with a maximum thickness of about $1830 \mathrm{~m}[5,17,18]$. The Cunningham, Britt, Spiers, Boatwright, and Springer make up the formations of the Springer Group [19-21]. These sands are believed to have originated from the Wichita Mountain uplift from the south, creating deep water submarine fans $[5,22,23]$. Possible reservoirs within the Springer Sands can be derived from upper and middle fan channels, sheet sands, feeder channels, and distal fan sheet sands [24]. The Springer shale lies at the base of the Springer Group (Figure 1) and is associated with the Noble Ranch Group, nearing the end of the Chesterian age, as supported by lithology and fauna fossil presence [25-28]. It is believed that the Springer was deposited during a sea level regression and correlates to a deep water submarine fan $[5,29]$.

2.2. Well Log Interpretation. There are three Springer shale "markers" (termed as Goddard M-1, M-2, and M-3 from the top to bottom) above the Caney Formation and below the Springer Sands (Figure 1). Varying in thickness, each marker has its own unique characteristics and log signature. As the uppermost marker (M-1) is the target of this study, it is necessary to define its extent. To pick the Springer shale on logs, the gamma ray and resistivity curves are the key, with the density-neutron curves providing additional data when needed. The log characteristic of the uppermost Springer shale changes, depending on locations in the SCOOP. Typical log characteristics show a gamma ray signature hovering around 90-130 API (American Petroleum Institute) units with spikes up to 150-200 API. A fluctuating resistivity value of 25-50 ohms is associated with the Springer as well. There is generally a spike in gamma ray and sharp decrease in resistivity at the base [30].

2.3. Sample Acquisition. The samples obtained for this study are from two wells (A and B) denoted as stars on Figure 1, and the names of the wells and company that supplied the samples remain confidential. As the target of this study, the Springer shale consists of organic-rich, gray, soft, siliceous to argillaceous fissile shale [31].

The samples from well A consisted of 3 sidewall cores from depths of $12,809^{\prime}, 12,847^{\prime}$, and $12,871^{\prime}$, shipped in sample tubes with cushioned packaging. The samples from well B came from depths of $12,945^{\prime}, 13,010^{\prime}$, and $13,046^{\prime}$ and were hand cut from a whole core and therefore larger sized than those from well A. The sample names and basic information are listed in Table 1. Both wells A and B are horizontal wells targeting the Woodford shale to produce both gas and oil. For example, completed on Jan. 22, 2014, with a true vertical depth of $14,771 \mathrm{ft}$ and lateral length of $7014 \mathrm{ft}$, well B has produced a cumulative amount of 2.57 billion cubic feet of gas, 78,412 barrels of oil, and no water [32].

Following the photographic recordkeeping, the samples were marked with a red pencil to denote lamination direction. The samples were then dry cut using a circular saw (6" Lapidary Trim Saw, Kingsley North) into six $1 \mathrm{~cm}$-sided cubes from each depth. The red pencil mark was intended to be visible after cutting and was used to identify and mark the top and bottom of the sample from the lamination direction. The bottom of the sample, labeled "B," was the main side for testing fluid imbibition and DI (deionized) water vapor absorption. The top of the sample was labeled "P" to represent B-to-P flow direction to be parallel to the lamination. Cubes used for fluid imbibition and vapor absorption tests were epoxied on every face except for the B and P faces to allow for "one-dimensional" flow through the sample; cubes for mercury injection capillary pressure (MICP) tests were not epoxied. Following the epoxying, the samples were cured, placed in glass vials, and dried in a $60^{\circ} \mathrm{C}$ oven.

2.4. TOC, Vitrinite Reflectance, and X-Ray Diffraction. TOC and vitrinite reflectance $R_{o}$, from the intensity of reflected light using polished vitrinite particles, were determined by following the standard methods of $[33,34]$ in China, respectively. Using powder samples of $<75 \mu \mathrm{m}$, X-ray diffraction (XRD) analysis was performed on MAXima_X XRD-7000 (Shimadzu) to identify mineral composition of samples following the methods of $[35,36]$. The scanning parameters for a bulk scan are from $2^{\circ} 2 \theta$ to $70^{\circ} 2 \theta$ at a step size of $0.02^{\circ}$. MDI Jade ${ }^{\mathrm{TM}} 9+$ software and ICDD PDF 4+ 2017 database with over 790,000 known compounds and RDB mineral subset of 8500 minerals are used to identify mineral phases present in the bulk diffractograms.

2.5. Mercury Injection Capillary Pressure (MICP). The MICP approach to pore structure characterization involves the use of nonwetting mercury applied at a pressure up to 60,000 psia (413 MPa), with a Micromeritics' AutoPore IV 9510 (Norcross GA), to overcome the capillary pressure and invade the pore throats of shale samples. Mercury is unique in that it acts as a nonwetting fluid in porous media, requiring external pressure to invade pore throats. As the intruding pressure gradually increases, smaller pore throats are incrementally invaded, thus creating a distribution curve of pore-throat sizes [37, 38].

The Washburn equation is used to determine the pressure to pore-throat relationship, assuming that the pores are cylindrical [39]. Wang et al. [40] reported that pore sizes calculated with Washburn equation based on the assumption of constant contact angle and surface tension will yield an error of $8 \% \sim 44 \%$ when pore spaces are in $\mathrm{nm}$ ranges. This work adopted the variable surface tension and contact angle approach of Wang et al. [40] to obtain the corrected pore- 


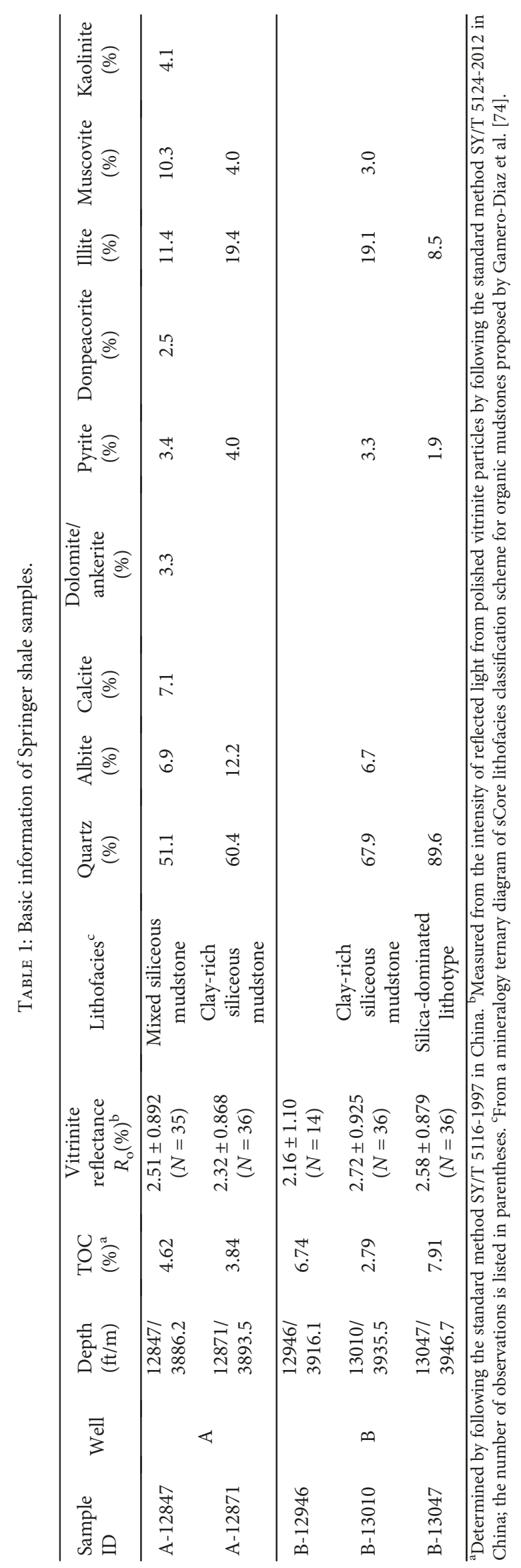


throat diameters for each intrusion pressure in shale samples. The range of pore-throat sizes detected is $2.8 \mathrm{~nm}$ (limited by the maximum intrusion pressure of the instrument) to $50 \mu \mathrm{m}$ (related to the penetrometer suitable for samples with a low porosity of about $0.1 \sim 5.0 \%$ in range) in diameter for tight shale samples.

A singular piece of $1 \mathrm{~cm}^{3}$ sample from each well was originally oven dried at $60^{\circ} \mathrm{C}$ for at least 3 days to remove any residual moisture in connected pore space. The sample was then placed in a Drykeeper (Bel-Art) to cool to room temperature of $23^{\circ} \mathrm{C}$ while keeping the humidity below $10 \%$ to avoid any moisture intruding the sample during the cooling process [37]. To begin the testing, the sample was placed into a penetrometer, which is an apparatus consisting of a sample chamber connected to a metal precision bore and glass capillary system. Once the sample was sealed, the entire penetrometer apparatus was placed into a low pressure chamber that was evacuated to $50 \mu \mathrm{m} \mathrm{Hg}$ ( 0.05 torr, $0.000972 \mathrm{psi}$, $6.7 \mathrm{pa}$ ). The evacuation process removes any air or moisture in the machine and inside the sample. Then the sample underwent both low- and high-pressure analyses. The lowpressure analysis involves filling the sample chamber with mercury to a maximum of $30 \mathrm{psia}$ at an equilibrium time of $10 \mathrm{sec}$ between each pressure step. In high-pressure testing, the pressure is increased in steps from 30 psia up to 60,000 psia with an equilibrium time of 45 seconds for each step. The high-pressure analysis allows the mercury to invade pore throats as small as $2.8 \mathrm{~nm}$, with the correction method of Wang et al. [40].

The MICP method determines a range of pore structure characteristics, including a direct measurement of the bulk and particle densities, porosity, total pore volume, and median pore-throat diameter, as well as empirical estimate of total pore surface area [41], permeability with $1[42,43]$, and tortuosity with $2[11,13,44]$.

$$
\begin{aligned}
& k=\frac{1}{89} \frac{L_{\text {max }}^{3}}{L_{t}} \varphi S\left(L_{\text {max }}\right), \\
& \tau=\sqrt{\frac{\rho}{24 k\left(1+\rho V_{\text {tot }}\right)} \int_{r_{c} \text { min }}^{r_{\text {, } \max }} r_{c}^{2} f_{v}\left(r_{c}\right) d r_{c}}=\frac{D_{0}}{D_{e}}=\frac{1}{\varphi}\left(\frac{L_{e}}{L}\right)^{2} .
\end{aligned}
$$

2.6. Wettability. The wettability test observes the surface wetting characteristics of the sample and determines whether the shale is wetting or nonwetting to deionized (DI) water, ndecane, or API brine $\left(8 \% \mathrm{NaCl}\right.$ and $2 \% \mathrm{CaCl}_{2}$ by weight [45]). This test was conducted with flat fragments recovered from the cutting process, which were further grinded off visible cutting marks with sandpaper. One drop of fluid $(2 \mu \mathrm{L})$ from a pipette was applied to wet the surface of each sample to observe the spreading of the liquid with video recording using a microscopic camera (Dino-Lite Edge Am4815Zt, AnMo Electronics Corporation). A qualitative number was assigned for the spreading behavior after $30 \mathrm{sec}-$ onds liquid-surface contact; number 1 designates no spreading at all, while the number 10 denotes perfect spreading of the fluid on the sample. These qualitative wettability assessments are later confirmed for other shale samples (e.g., Bakken, Niobrara, and Utica) in our laboratory performed on a contact angle meter and interface tensiometer (Model SL200KB, Kino).

2.7. Fluid Imbibition and Vapor Absorption. Fluid imbibition can either be forced via an externally applied pressure or spontaneous if the sample pores are partially wet with the same type of imbibed fluid [46, 47]. The process of spontaneous imbibition is controlled by capillary forces within the porous media as the fluid is imbibed [48-50]. The rate at which the fluid is imbibed is controlled by the porosity of the media, the wetting fluid, and the interaction between the media and fluid itself [51]. Three fluids (DI water, API brine, and n-decane) were used to study spontaneous imbibition in the Springer shale. Such a study demonstrates the pore connectivity of the formation, along with the interaction between different fluids in the sample. While this test is relatively quick (24 hour average), the use of three fluids provides a model for the overall reservoir quality of the formation by using percolation theory [52]. Pore connectivity of a porous medium towards the fluid is assessed from the slope of a graph of log-imbibed liquid versus log time; the range of resultant slopes indicates the general connectivity of the pores. The beginning of the tests generally has a higher slope $(+0.5)$ due to the edge accessible porosity in direct contact with the sample that are filled first. As the test continues, the slopes become lower in value due to the fluid moving its way through the sample only via connected, but tortuous, pore spaces. If the slope becomes a negative number or zero, the fluid has either stopped moving through the pores, or the fluid front has reached the sample top.

Now, we detail the procedure used in the imbibition and vapor tests. The $1 \mathrm{~cm}^{3}$ samples were initially dried in the $60^{\circ} \mathrm{C}$ oven for a period of at least 48 hours. A petri dish $(14.64 \mathrm{~cm}$ diameter and $1.90 \mathrm{~cm}$ height $)$ was filled half full with the desired testing fluid (DI water, API brine, or $\mathrm{n}$-decane) and weighed and recorded. The dish was then placed inside a closed chamber beneath the electronic balance (Shimadzu Analytical Balance AUW22OD, with a precision of $0.01 \mathrm{mg}$ ) as shown in Figure 2. For DI water or brine tests, there were two beakers filled with water inside the chamber to keep the humidity constant throughout the test. The chamber itself rested on a Newport 271 High Load Lab Jack that moved in the vertical direction by a twistable lever. The bottom of the balance had a hook that weighs the sample hanging beneath, and the balance was connected to a computer that uses an Excel file to record the weight of the sample at specific time intervals over the duration of the test.

After the sample had been inside the Drykeeper for more than 20 minutes to cool down, the sample was weighed using the analytical balance and then placed inside the sample holder composed of a plastic cap and screws that secure the sample to avoid the sample being slumping during the test. Aluminum foil was placed inside the holder between the contact of the holder and the exposed top face of the sample. The sample holder was weighed and hung inside the chamber. The hanging sample was completely still, before testing began 


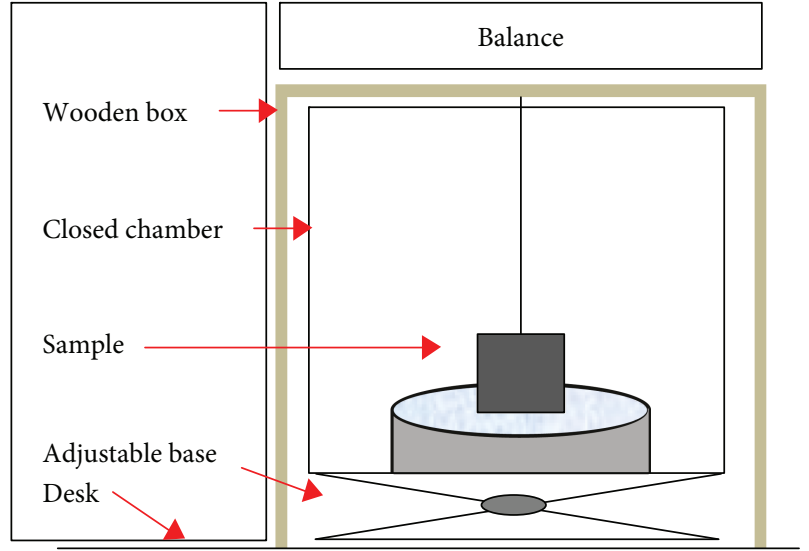

FIgURE 2: Setup for imbibition and vapor absorption tests.

to avoid inaccurate data at the beginning of the test due to the motion of the apparatus. Once the sample was no longer moving and the balance and computer were set up, the test could begin. As shown in Figure 2, the sample remains in the same position while the adjustable base is raised towards the sample. For imbibition, the base is raised until the lower $1-2 \mathrm{~mm}$ of the sample is submerged in the fluid. Vapor absorption is set up the same way as the imbibition, but the sample is not submerged but hangs roughly $2-4 \mathrm{~cm}$ above the fluid. The imbibition experiment was repeated over time periods of 12, 24, and 48 hours, while the vapor absorption test lasts for 7 days.

The balance was instructed to send weight data to the computer and log the sample weight change over the testing period. The weighting interval was initially every 1 second for 2 minutes, then every 30 seconds for about 1 hour, followed by every 2 minutes for about 6 hours. The final interval for imbibition is 5 minutes for the remainder of the test, generally 18 hours. For vapor absorption, at the 24-hour mark, the interval is set to record every 10 minutes for the remaining 6 days of the test. Spot checks were taken during the tests to verify the weight data (on the balance) and elapsed time, with these logged in the Excel file.

The testing fluids (DI water, API brine, or n-decane) each has distinct characteristics that make them valuable testing fluids. Repeated at several different imbibition times by redrying the samples, DI water was used to determine the connectivity of water-wetting pore network in the sample and observe how long it took the fluid to pass through the entire sample, if at all. Once this time frame was determined, the other fluid testing periods were accordingly selected, knowing that $\mathrm{n}$-decane would move through the samples at a quicker rate, due to its wetting behavior towards Springer shale shown from the wettability tests. As a nonpolar fluid and oil surrogate, $\mathrm{n}$-decane was used on certain samples in conjunction with tracers to examine the movement of this fluid in hydrophobic pore systems.

Once the desired testing time is completed, the final weight of the sample is recorded and the balance is turned to the standby mode to stop the recording. A Kimwipe is slightly wetted with the testing fluid and weighed. The sample and sample holder are removed from the chamber, and the Kimwipe is dabbed on the face of the sample bottom that was submerged in the fluid to catch any residual fluid that may be adhered to the face of the sample. The Kimwipe is then weighed again to record any weight change from contact with the sample. The sample and holder are weighed, along with the sample itself. The petri dish with fluid is weighed next to observe the fluid loss from the dish. Once the final measurements have been taken and recorded, the data processing and analysis of the test results begin, following $\mathrm{Hu}$ et al. [53].

2.8. Tracer Migration during Imbibition. In addition to tracer-free imbibition and vapor absorption tests with DI water, imbibition experiments of tracer-containing API brine and $\mathrm{n}$-decane were conducted. The API brine fluid contains tracer chemicals of potassium perrhenate, cesium iodide, samarium iodide, europium bromide, antimony and ruthenium complexes, and CdS quantum dot particles. Similarly, n-decane fluid includes two organic-phase molecular tracers with different sizes: 1-iododecane $\left\{\mathrm{CH}_{3}\left(\mathrm{CH}_{2}\right)_{9} \mathrm{I}\right.$, molecular weight of $268.18 \mathrm{~g} / \mathrm{mol}$; referred as organic-I in this work $\}$ and trichlorooxobis (triphenylphosphine) rhe$\operatorname{nium}(\mathrm{V})\left\{\left[\left(\mathrm{C}_{6} \mathrm{H}_{5}\right)_{3} \mathrm{P}\right]_{2} \mathrm{ReOCl}_{3}\right.$, molecular weight $833.14 \mathrm{~g} /$ mol; referred as organic-Re\}. The development and utility of a range of tracers in both polar and nonpolar fluids to study dual wettability and dual connectivity of hydrophilic and hydrophobic pore networks in shale are documented in detail in Hu et al. [54].

After tracer imbibition test of $24 \mathrm{hrs}$, the shale sample was lifted out of the fluid reservoir, flash-frozen with liquid nitrogen, kept at $-80^{\circ} \mathrm{C}$ in a freezer, freeze-dried as a batch at $-50^{\circ} \mathrm{C}$ and near-vacuum (less than $1 \mathrm{~Pa}$ ) for 48 hours, then stored at $<10 \%$ relative humidity prior to tracer mapping analyses by laser ablation inductively coupled plasma mass spectrometry (LA-ICP-MS) [11, 13, 55]. The instruments used are laser ablation system (UP-213; New Wave, Freemont, CA) and ICP-MS (ELAN DRC II; PerkinElmer/ SCIEX, Sheldon, CT).

\section{Results and Discussion}

3.1. Pore Structure Characteristics. The data processing of MICP tests is shown for sample B-13010 as an example. Springer shale samples have multiple pore-throat size distributions in $\mu \mathrm{m}-\mathrm{nm}$ ranges, but mostly centering on $10 \mathrm{~nm}$ in pore-throat sizes [13]. Therefore, an intensive sampling at the high-pressure region is employed (Figure 3C). For lowpressure region with a small change of intrusion volumes, the results are resized to identify the inflection points $\mathrm{L}_{\mathrm{t}}$ for each connected pore network (Figure $3 \mathrm{~A}$ ), from which $\mathrm{L}_{\max }$ is calculated (Figure $3 \mathrm{~B}$ ) to obtain the values of permeability and tortuosity via 1 and 2 [13].

For the Springer shale, MICP tests provide the pore structure results including bulk and particle densities, porosity, pore-throat size distribution, permeability, and both effective and geometrical tortuosities (shown in Table 2); the effective tortuosity $\left(\mathrm{D}_{0} / \mathrm{D}_{\mathrm{e}}\right)$ is related to the extent of diffusive mass transfer while geometrical tortuosity $\left(\mathrm{L}_{\mathrm{e}} / \mathrm{L}\right)$ to tortuous pathways $[11,13]$. Out of a total of five Springer shale samples, 


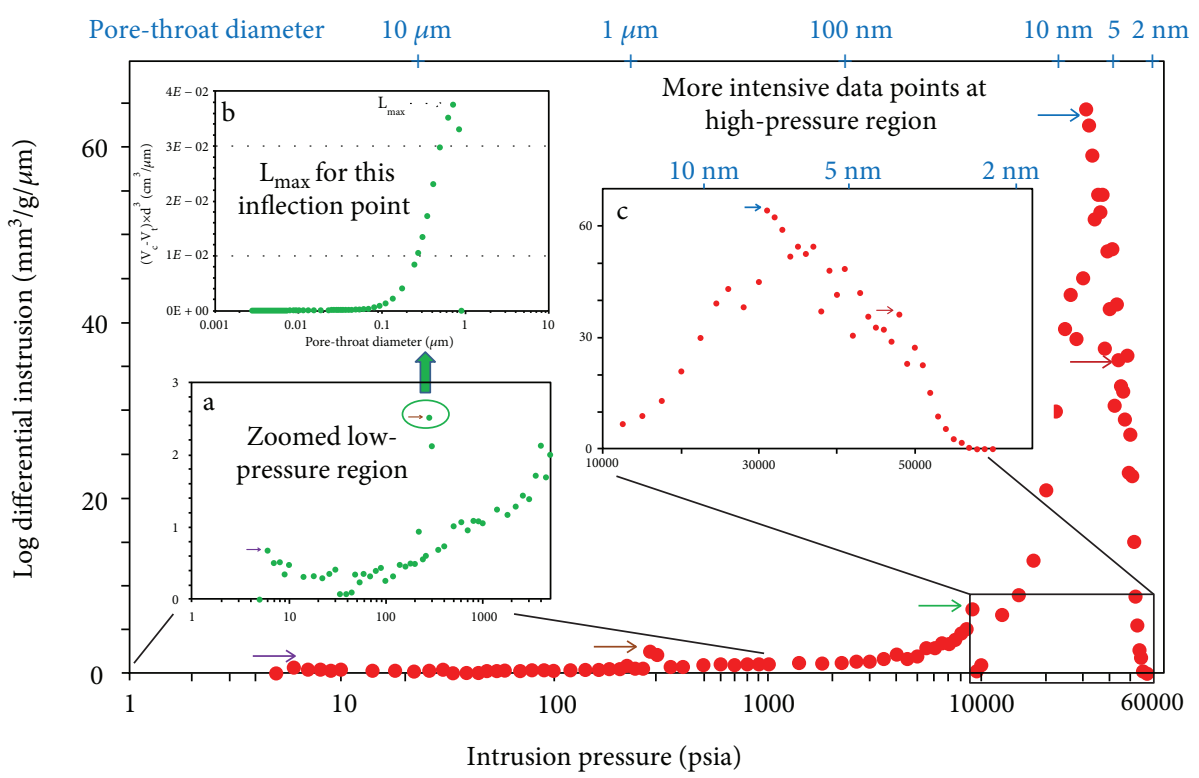

Figure 3: Log differential intrusion versus intrusion pressure for example sample B-13010: (a) zoomed view for the identification of inflection points; (b) calculation of $\mathrm{L}_{\max }$ from an inflection point; (c) intensive data collection points at high-pressure region to investigate pore volumes with sub-nm sized pore throats.

four (except for sample B-13047) exhibit similar behavior, probably are related to their similar lithofacies (Figures 4 and 5). These four samples have a porosity of $6.32 \pm 0.75 \%$ and permeability of $20.0 \pm 6.52 \mathrm{nD}$; this is consistent with the reported porosity of 3-9\% in EDGAR Online [14]. As a comparison, the porosity and permeability values for sample B-13047 are smaller at $2.48 \%$ and $2.42 \mathrm{nD}$. Shale porosity is influenced by multiple factors, such as grain size distribution and packing, TOC and maturation, and mineral composition $[13,56]$. This study, as well as ours on Eagle Ford, SpraberryWolfcamp, and Niobrara shales, indicates the importance of lithofacies on porosity and even more on pore-throat size distribution. Clay-rich siliceous mudstone, including sample B-13010, shows a predominant pore-throat size at $5-50 \mathrm{~nm}$ to account for $77.0 \pm 4.87 \%$ of total pore volume, while pore-throat sizes for the silica-dominated lithotype sample B-13047 are centered around $2.8-10 \mathrm{~nm}$ at $72.0 \%$ (Table 2; Figures 4 and 5).

Bulk and particle densities of all five Springer range from $2.19-2.67$ to $2.36-2.81 \mathrm{~g} / \mathrm{cm}^{3}$, with no apparent trend with the depth. For four clay-rich siliceous mudstone samples, total pore area and pore volumes are $13.9 \pm 3.44 \mathrm{~m}^{2} / \mathrm{g}$ and $26.9 \pm 4.96 \mathrm{~mm}^{3} / \mathrm{g}$, respectively.

Both intrusion and extrusion tests were performed for MICP, much hysteresis effect is noticed, with $70.0 \pm 8.1 \%$ mercury retained inside complex pore networks without being released when the pressure returns to the starting one of 5 psi (Table 2). The tortuosity value can be used to determine the geometrical aspect of fluid movement inside porous media; high tortuosity values indicate that fluids will have a difficult time getting through the sample. It is defined as the ratio of actual distance traveled between two points to the minimum distance between the two points $[57,58]$. MICP-derived tortuosity values are shown in Table 2, with $5.60 \pm 1.15(N=4)$ for clay-rich siliceous mudstone and
9.39 for silica-dominated lithotype sample B-13047. Using the same procedures, the Barnett shale has a tortuosity range of 1.99 to 12.2 with the majority being $8-12$ [10], indicating that it takes less effort for fluids to move through most of the Springer shale samples compared to the Barnett shale.

There has been a significant amount of work determining pore sizes and types in shales [11, 59-66]. Organic matterhosted pores are generally sub- $\mu \mathrm{m}$ in size and are proven to be a significant component of shales such as the Barnett, Woodford, and Horn River shales [67]. Organic matter pores smaller than $10 \mathrm{~nm}$ in size are difficult to see on SEM images, while MICP, being excellent for volume and size determination down to $2.8 \mathrm{~nm}$ [11], cannot differentiate between different pore types [67]. Working on the differences in pore sizes in the Eagle Ford Shale with different maturity, Pommer and Milliken [68] concluded that organic matter-hosted pores have an average size of $13.2 \mathrm{~nm}$ or smaller, while mineralbased pores have an average size of $30.2 \mathrm{~nm}$. Using these info, the percentage of pores $13.2 \mathrm{~nm}$ or smaller in the Springer shale is $59.7 \pm 15.8 \%(N=5)$, indicating its importance and influence on wettability. This coincides with the idea of mineral pores being destroyed during early compaction by cementation and infill, thus transitioning the majority of pores from mineral grain pores to organic matter-hosted pores in mature shale [68]. Field emission-SEM imaging work is ongoing to confirm that the majority of pores in the Springer shale are organic matter-hosted, as complementary and multiple approaches are needed to investigate pore size, type, and volume distribution to have a complete picture of shale pore structure.

3.2. Wettability. Droplet wettability experiments using DI water, API brine, and n-decane were performed on the Springer shale samples. On a scale of 1 to 10,1 being no spreading at all and 10 being perfect spreading across the 


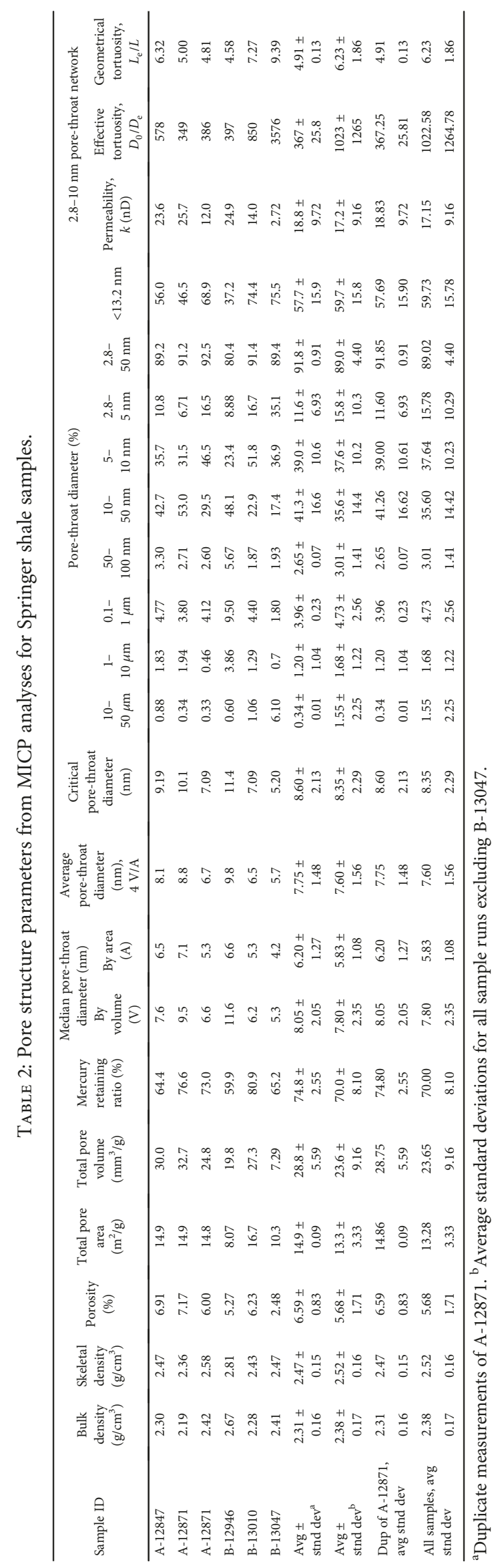




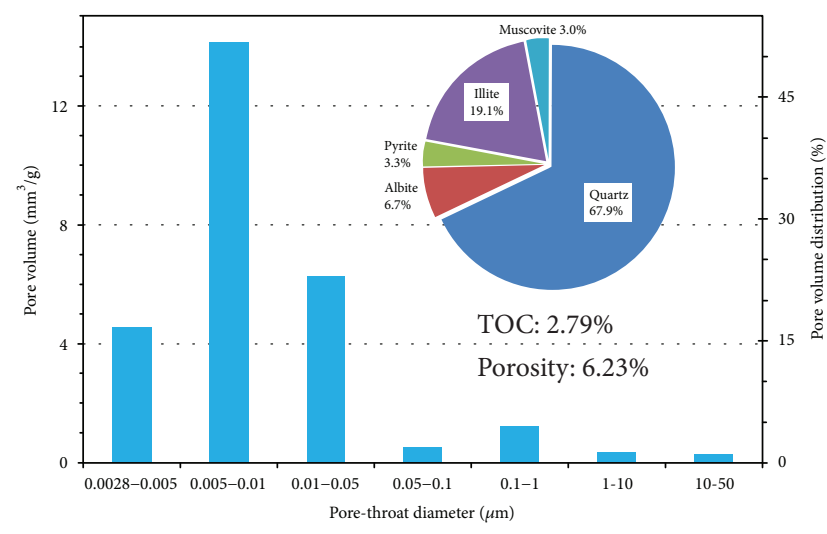

(a)

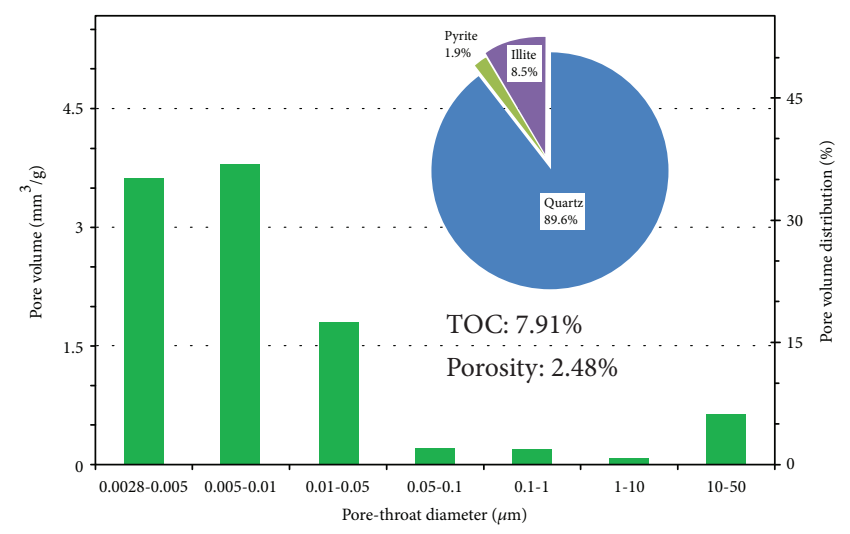

(b)

FIgURE 4: Pore-throat size distribution versus mineralogy for (a) B-13010 and (b) B-13047; QFM: quartz, feldspars, and mica.

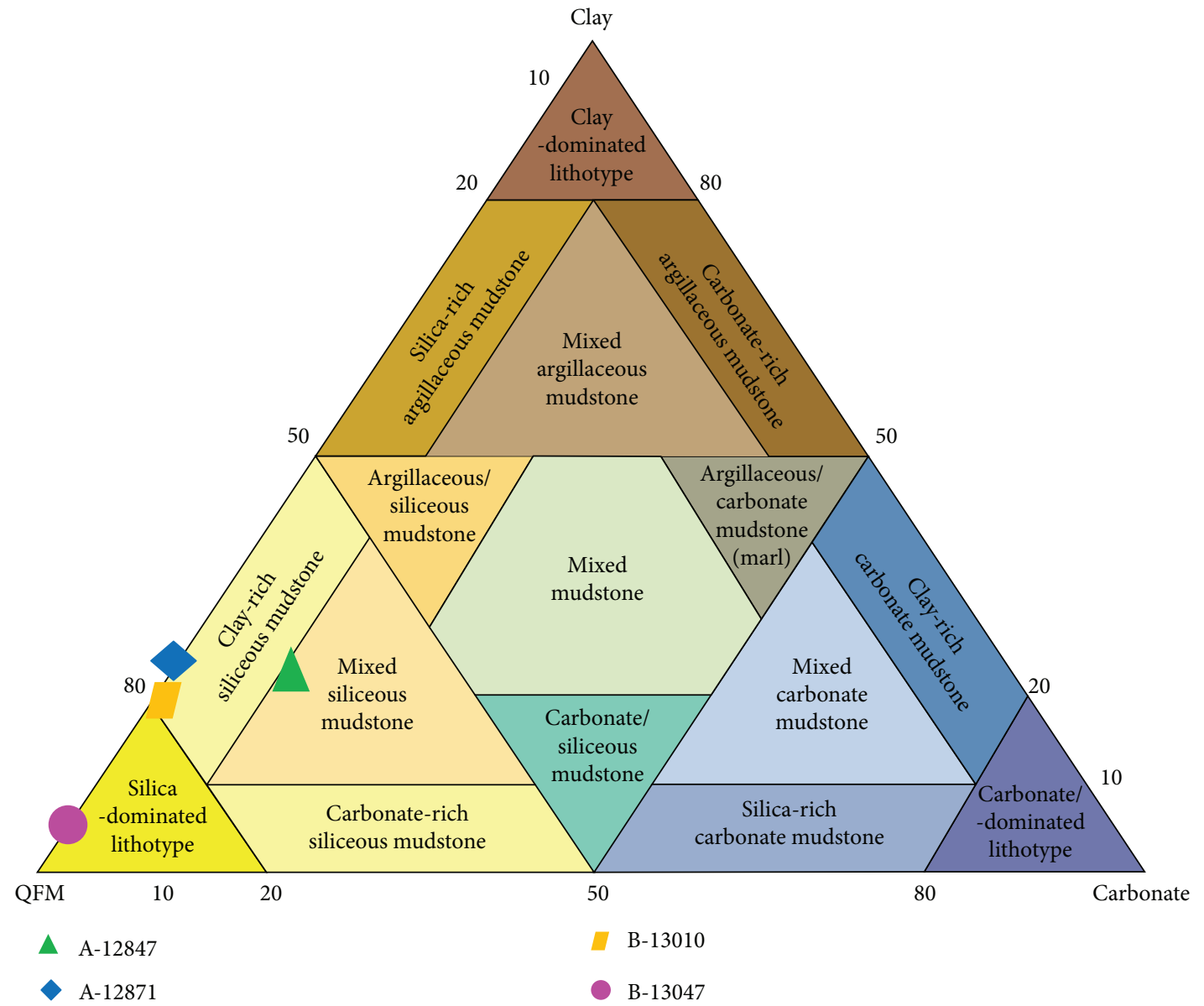

FIGURE 5: A ternary diagram for sCore lithofacies classification scheme for organic mudstones proposed by Gamero-Diaz et al. [74].

sample, the samples from both wells had values of 9 and 10 for n-decane (Figure 6; Table 3) so are oil wetting on the observational scale of several millimeters in area. The lower values for DI water and API brine (Table 3 ) indicate modest water-wetting characteristics. Overall, the Springer shale has a Dalmatian wettability, consistent with many other shales examined in our research group, which show excellent oil-wetting while different extents of water-wetting.
The organic fluid (n-decane) is expected to be preferentially attracted to the hydrophobic component (organic matter such as kerogen, bitumen, pyrobitumen, and dead oil [69]) of the shale matrix.

Comparatively speaking, the Springer shale exhibits a noticeably higher tendency to water-wetting, indicating a lower surface tension and the possibility that the shale could take in more water than desired during the hydraulic 


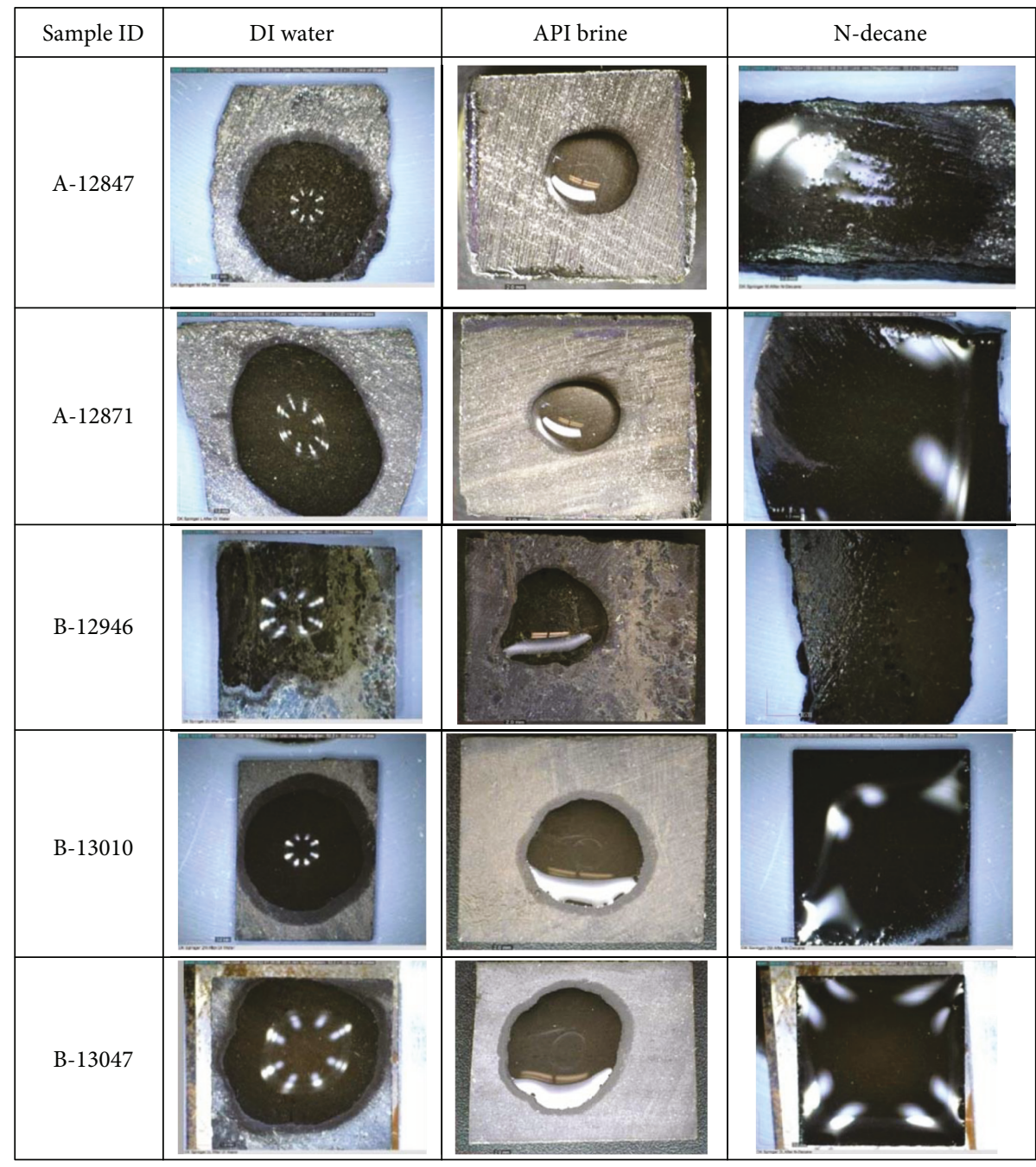

Figure 6: Photos of droplet wettability tests. Some shining spots are from the lighting effects.

TABLE 3: Wetting characteristics of the Springer shale samples from droplet wettability tests. A qualitative number is assigned for the spreading behavior over 30 seconds: number one designates no spreading at all, while number 10 represents a perfect spreading of the fluid on the sample surface.

\begin{tabular}{lccc}
\hline Sample ID & DI water & API brine & n-decane \\
\hline A-12847 & 6 & 2 & 10 \\
A-12871 & 7 & 2 & $10-$ \\
B-12946 & 8 & 3 & 10 \\
B-13010 & 5 & 5 & 9 \\
B-13047 & 8 & 5 & 9 \\
\hline
\end{tabular}

fracturing. An understanding of the distribution and migration of the hydrocarbons stored in these organic matterhosted pores, as well as their interactions with hydrophilic pore system, is critically needed, through a usage of nanosized hydrophobic and hydrophilic tracers [54]. API brine is water-wetting but with a high salinity to mimic formation fluid. All five Springer shale samples exhibit a lower affinity for API brine than for DI water (Table 3). Working with mica powder, kaolinite, and montmorillonite, Gomari and Joseph [70] found that clay content plays a significant role in producing higher contact angles for brines.

3.3. Spontaneous Fluid Imbibition and Vapor Absorption. Spontaneous imbibition is the process of a fluid imbibing into the face of a sample over a period of time. The fluids used in this study include DI water, n-decane, and API brine to study their interaction with and movement in Springer shale. DI water tests were replicate measurements consisting of a 12-, 24-, and/or 48-hour time periods with a drying period in between to remove any residual water in connected pore spaces. Their imbibition slopes, in the graph of log cumulative mass versus log time, were shown in Table 4. After scattered data up to about $10 \mathrm{sec}$ at the beginning of the tests caused by the sample settling into the fluid, there could have three slope values for regions with different periods of time for DI water tests (as shown in Figure 7): the high first slope in phase 1 (with a short duration of less than 20 seconds, if discernable; as shown in Figure 7a) is attributed to the adhering external menisci [71]; the second slope for phase II (within a few minutes) is associated with the fluid migrating 
TABLE 4: Spontaneous imbibition test results. Both API brine and n-decane tests contain tracers.

\begin{tabular}{|c|c|c|c|c|}
\hline Sample ID & Fluid & Method & Sample dimensions $(\mathrm{cm})$ & Connectivity slope \\
\hline \multirow{4}{*}{ A-12847 } & & Imbibition & \multirow{2}{*}{$1.029 \mathrm{~L} \times 0.958 \mathrm{~W} \times 1.079 \mathrm{H}$} & $0.157 ; 0.252$ \\
\hline & DI water & Vapor absorption & & 0.407 \\
\hline & API brine & Imbibition & $1.039 \mathrm{~L} \times 0.911 \mathrm{~W} \times 1.043 \mathrm{H}$ & 0.478 \\
\hline & n-decane & Imbibition & $1.021 \mathrm{~L} \times 1.040 \mathrm{~W} \times 1.008 \mathrm{H}$ & 0.521 \\
\hline \multirow{4}{*}{ A-12871 } & & Imbibition & \multirow{2}{*}{$1.032 \mathrm{~L} \times 1.047 \mathrm{~W} \times 1.052 \mathrm{H}$} & $0.145 ; 0.184 ; 0.348$ \\
\hline & DI water & Vapor absorption & & 0.488 \\
\hline & API brine & & $1.033 \mathrm{~L} \times 0.925 \mathrm{~W} \times 1.065 \mathrm{H}$ & 0.502 \\
\hline & n-decane & & $1.029 \mathrm{~L} \times 1.078 \mathrm{~W} \times 0.994 \mathrm{H}$ & 0.499 \\
\hline \multirow{4}{*}{ B-12946 } & & Imbibition & \multirow{2}{*}{$1.110 \mathrm{~L} \times 1.040 \mathrm{~W} \times 0.960 \mathrm{H}$} & $0.142 ; 0.264$ \\
\hline & DI water & Vapor absorption & & 0.487 \\
\hline & API brine & & $1.040 \mathrm{~L} \times 1.040 \mathrm{~W} \times 1.030 \mathrm{H}$ & 0.394 \\
\hline & n-decane & & $1.010 \mathrm{~L} \times 1.090 \mathrm{~W} \times 1.100 \mathrm{H}$ & 0.530 \\
\hline \multirow{4}{*}{ B-13010 } & & Imbibition & \multirow{2}{*}{$1.000 \mathrm{~L} \times 1.010 \mathrm{~W} \times 0.970 \mathrm{H}$} & $0.191 ; 0.279 ; 0.311$ \\
\hline & DI water & Vapor absorption & & 0.497 \\
\hline & API brine & & $0.970 \mathrm{~L} \times 1.210 \mathrm{~W} \times 1.070 \mathrm{H}$ & 0.170 \\
\hline & n-decane & & $0.990 \mathrm{~L} \times 0.930 \mathrm{~W} \times 1.080 \mathrm{H}$ & 0.752 \\
\hline \multirow{4}{*}{ B-13047 } & DI water & Imbibition & \multirow{2}{*}{$1.040 \mathrm{~L} \times 1.020 \mathrm{~W} \times 1.095 \mathrm{H}$} & $0.194 ; 0.330$ \\
\hline & DI water & Vapor absorption & & 0.499 \\
\hline & API brine & & $0.990 \mathrm{~L} \times 1.050 \mathrm{~W} \times 0.950 \mathrm{H}$ & 0.174 \\
\hline & n-decane & & $0.990 \mathrm{~L} \times 1.030 \mathrm{~W} \times 1.050 \mathrm{H}$ & 0.549 \\
\hline
\end{tabular}

up the exterior of the sample (bottom and wall faces), and along fast pathways such as microfractures and laminations (if present), with good edge-accessible pore connectivity (such a surface zone is approximately $400 \mu \mathrm{m}$ in length for the Barnett shale [10]); the third slope of phase III (long duration in hours) indicates the rate of fluid movement inside and pore connectivity (termed as connectivity slope in this work) of the shale matrix.

The DI water imbibition slopes range from 0.145 to 0.348 , indicating that the Springer has low pore connectivity towards water, consistent with the wettability tests (Tables 3 and 4). Imbibition tests with API brine have slopes of 0.478 , $0.502,0.394,0.170$, and 0.174 for five Springer samples, with the first three samples (A-12847, A-12871, and B-12946) showing a larger slope values (and better connectivity) than the DI water runs; this is also consistent with their surface wetting behavior (Table 3 ).

In addition, the connectivity slopes for both DI water and API brine are smaller than those of $n$-decane tests which have slopes of $0.521,0.499,0.530,0.752$, and 0.549 with an average of 0.570 (Table 4). For all n-decane tests, there is an additional small slope of approximately 0.1 after the connectivity slope, representative of the wetting $n$-decane reaching the sample top which is supported by visual observations at the conclusion of the testing period. Overall, in approximately $10 \mathrm{hrs}$ (3.5 hrs for sample B-13010, as shown in Figure 7c), the wetting front of $n$-decane reaches the sample top of $1 \mathrm{~cm}$ above the bottom. The drastic difference between the water/brine and n-decane connectivity slope values indicates that the Springer has a higher pore connectivity for oil-based fluids such as n-decane.
Different from the imbibition tests, vapor absorption of DI water into the Springer shale shows a slope of 0.5 to be indicative of diffusive behavior of vapor absorption and capillary condensation into connected pore networks towards water vapor [53]. Due to a lower hydraulic gradient than imbibition and consequently smaller water uptake, vapor absorption shows clearer durations for phases 1 and 2 (Figure $7 \mathrm{~b}$ ), though weights in phase 1 are scattered from initially small weight changes even for a microbalance with a sensitivity of $0.01 \mathrm{mg}$. The difference of connectivity slopes between vapor absorption and imbibition tests is consistently observed for other shales (e.g., Barnett, Eagle Ford, Niobrara, Muskwa, Otter Park, and Evie) studied in our laboratory and is related to fluid uptake dynamics as well as pore-throat size distributions and pore connectivity of shale. During vapor absorption tests, a vapor molecule will condense inside a capillary tube (pore throat) once the meniscus of the condensate is less than or equal to the diameter of the pore throat [71]. In addition, such a capillary condensation process can occur in multiple dimensions, as opposed to the one-sided imbibition tests which are limited by imbibing front. Therefore, capillary condensation can initially fill up small-sized nanopores, which are predominantly organic matter-hosted ones, and proceed to larger ones associated with minerals which have a high tendency to be water-wet. In the end, the vapor absorption tests show a fluid uptake scaling result indicative of well-connected pore networks. A recent study with mesoporous (with a pore diameter of $4 \mathrm{~nm}$ similar to the predominant pore-throat sizes of $5-6 \mathrm{~nm}$ in Springer shale) silica layers has found that the water vapor and fluid phases can exist together in nanoporous samples and that 


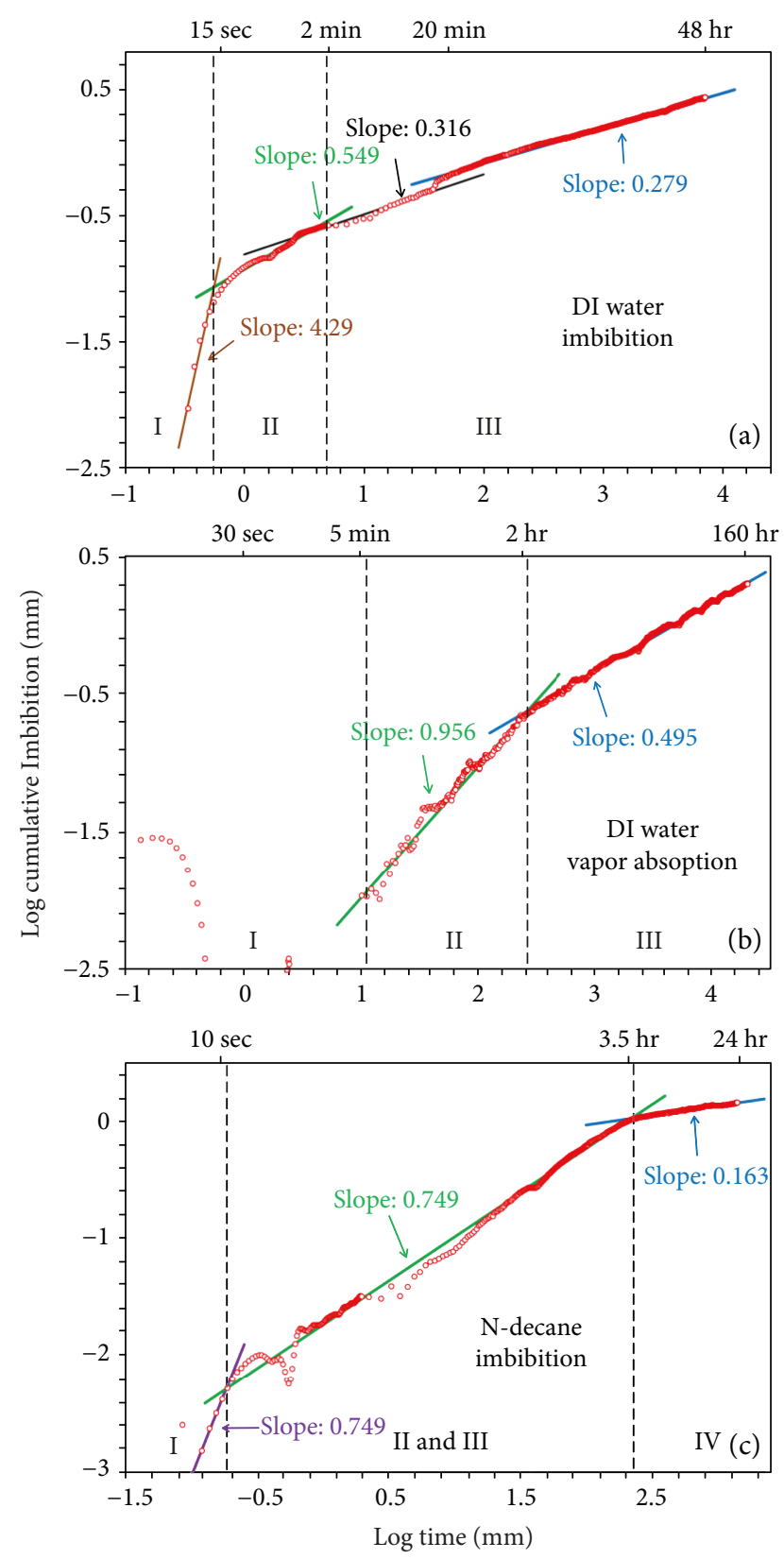

FIgure 7: Fluid imbibition ((a) DI water, (c) n-decane) and vapor absorption ((b) DI water) results for sample B-13010. Different phases of fluid uptake are indicated with vertical lines.

at a relative humidity above 0.65 capillary condensation triggers imbibition within the sample having both diffusion- and imbibition-like regimes result in invasion dynamics scaling as $t^{1 / 2}$ to be described by a modified Lucas-Washburn equation $[71,72]$. Working with $n$-alcohols $(n=4-10)$ of different vapor pressures and porous Vycor glass with an isotropic network of interconnected pores at a mean pore diameter of $7.5 \mathrm{~nm}$, Kiepsch and Pelster [71] reported a spontaneous capillary flow from capillary bridges close to the sample surfaces, which is indistinguishable from liquid uptake of imbibition.

3.4. Tracer Penetration during Spontaneous Imbibition. Considering the Dalmatian wettability of Springer shale, tracers in two fluids (API brine and n-decane) are used to interrogate the wettability and connectivity of hydrophilic and hydrophobic pore networks. Background (bkgd) levels (average \pm standard deviation; sampling points) obtained on a clean sample are presented, as well as the measured concentrations for each tracer at top, interior, and bottom faces. The LA-ICP-MS detection limits for I, Cs, and Re tracer elements are $0.5,0.5$, and 0.1 , respectively; these values are used as the smallest ones for 8 -scale color scheme (Figures 8 and 9). The largest value of color scale (e.g., $412 \mathrm{mg} / \mathrm{kg}$ for Cs in Figure 8) is the averaged concentration obtained on the bottom face; therefore, any color change from the interior face indicates the extent of tracer penetration.

Imbibition experiments with tracer-free DI water indicate that the pores in Springer shale are poorly connected for the movement of polar fluid. In addition to tracer-free fluid imbibition tests to probe the pore connectivity for a particular fluid, tracer imbibition tests were conducted and resultant tracer penetration distances were mapped using LA-ICP-MS (shown in Figure 8 for B-13010 as an example while other samples show the same behavior). When imbibition proceeds from this initially dry sample, capillary-driven advective flow could pull fluid and tracers upward to produce a relatively steep imbibition front for tracers. However, due to the weakly wetting nature of Springer shale to API brine, the presence of both $\mathrm{Cs}^{+}$and $\mathrm{ReO}_{4}{ }^{-}$is very limited to the sample bottom. For $\mathrm{Cs}^{+}$with a molecular size of $0.313 \pm$ $0.007 \mathrm{~nm}[73]$, the penetration distance is only up to approximately $1000 \mu \mathrm{m}$ into the matrix from the bottom after the imbibition duration of $24.3 \mathrm{hrs}$. For $\mathrm{ReO}_{4}{ }^{-}$with a molecular size of $0.553 \mathrm{~nm}$ [55], as well as $1 \mathrm{~nm}$-sized Sb-complex and $\mathrm{CdS}$ nanoparticles of 5-10 nm (results not shown), the penetration is even less than about $150 \mu \mathrm{m}$, which is the first sampling distance above the bottom edge. Sample B-13010 has a median pore-throat diameter of $6.2 \mathrm{~nm}$ (by volume) and $5.3 \mathrm{~nm}$ (by area), as well as average pore-throat diameter of $6.5 \mathrm{~nm}$ (Table 2). In other words, the connected pore network for polar fluid steeply decreases and the steric hindrance effect is significant even for molecules at a size of $0.5 \mathrm{~nm}$. Similar results are observed for Barnett shale [11] and Longmaxi shale [54].

On the contrary, the imbibition slope for n-decane fluid exhibits $1 / 2$ slope (Figure 7c), suggesting well-connected pore networks for the migration of nonpolar fluid, consistent with the tracer tests (Figure 9). After an imbibition test of $23.5 \mathrm{hrs}$, the smaller sized organic-I tracer occupies most pore spaces of the shale matrix, with the detected iodine concentrations consistently similar among the bottom, interior, and top faces; as a matter of fact, the wetting front of organic-I in $n$-decane might have reached the sample top at $1 \mathrm{~cm}$ at $3.5 \mathrm{hrs}$, as shown from the weight monitoring (Figure 7c). More importantly, the tracer penetration of wetting fluid is strongly affected by the molecular size, with the larger height/width of organic-Re leads to its molecular entanglement in pore networks with pore-throat sizes of only approximately $5 \mathrm{~nm}$, as shown from its absence of penetration (Figure 9B). As reported in $\mathrm{Hu}$ et al. [12], the organic-I has a diameter at $1.39 \mathrm{~nm}$ length $(\mathrm{L}) \times 0.29 \mathrm{~nm}$ width $(\mathrm{W}) \times 0.18 \mathrm{~nm}$ height $(\mathrm{H})$, while the structural 

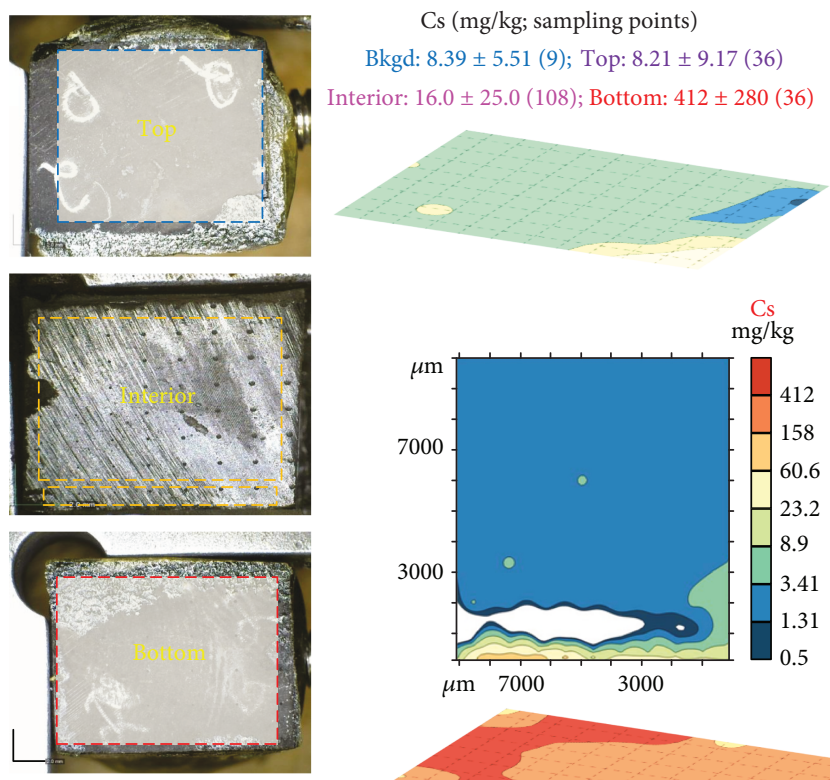

$\operatorname{Re}(\mathrm{mg} / \mathrm{kg}$; sampling points)

Bkgd: $0.16 \pm 0.13(9) ; \quad$ Top: $0.22 \pm 0.15(36)$

nterior: $16.0 \pm 25.0$ (108); Bottom: $412 \pm 280$ (36) Interior: $0.11 \pm 0.061$ (108); Bottom: $802 \pm 1189$ (36)
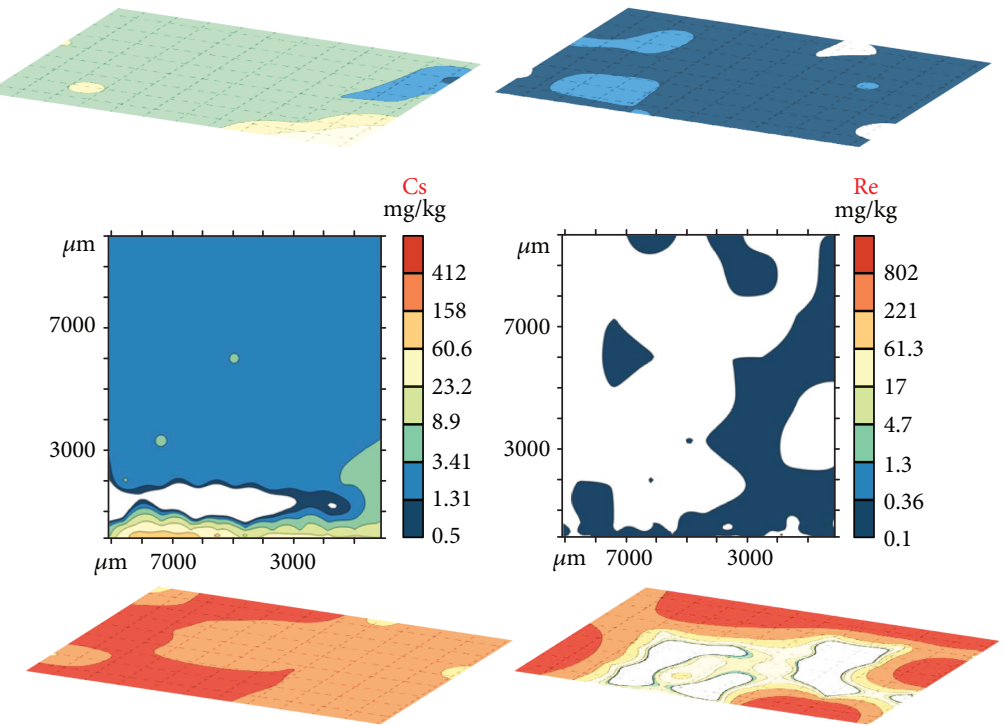

Figure 8: Imbibition of $\mathrm{Cs}^{+}$and $\mathrm{ReO}_{4}{ }^{-}$tracers in API brine into B-13010 sample of Springer shale, mapped on three faces (top, interior, and bottom; from top to bottom for each vertical panel of photos and tracer results, each tick on the $x$ - and $y$-axes has a scale of $1000 \mu \mathrm{m}$ ); imbibition time is $24.3 \mathrm{hrs}$. The laser spot size for sampling is $100 \mu \mathrm{m}$, while the interior grid sizes cover the whole sample and are mapped with a two-grid scheme of variable spacing between spots to catch the concentration change near the bottom edge, as shown in the interior photo on which the laser spots are visible. The bottom photo shows the custom-made aluminum chuck, with two screws (tip shown in the top photo, to the right) to place the sample during the tracer mapping. The white areas indicate the regions of tracer concentration below the detection limit of LA-ICP-MS approach.
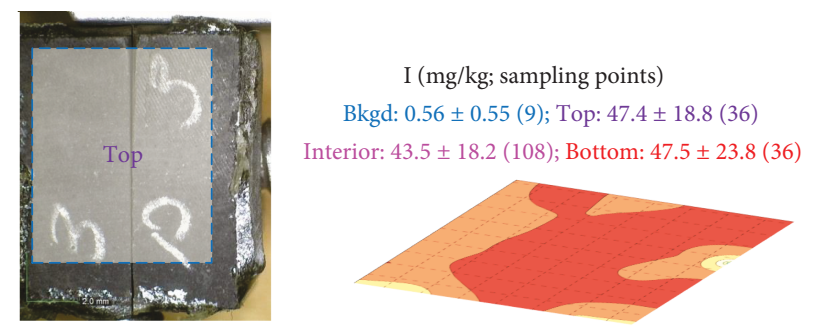

$\operatorname{Re}(\mathrm{mg} / \mathrm{kg}$; sampling points)

Bkgd: $0.17 \pm 0.14$ (9); Top: $3.60 \pm 12.1(36)$

Interior: $0.33 \pm 0.62(108)$; Bottom: $123 \pm 224(36)$
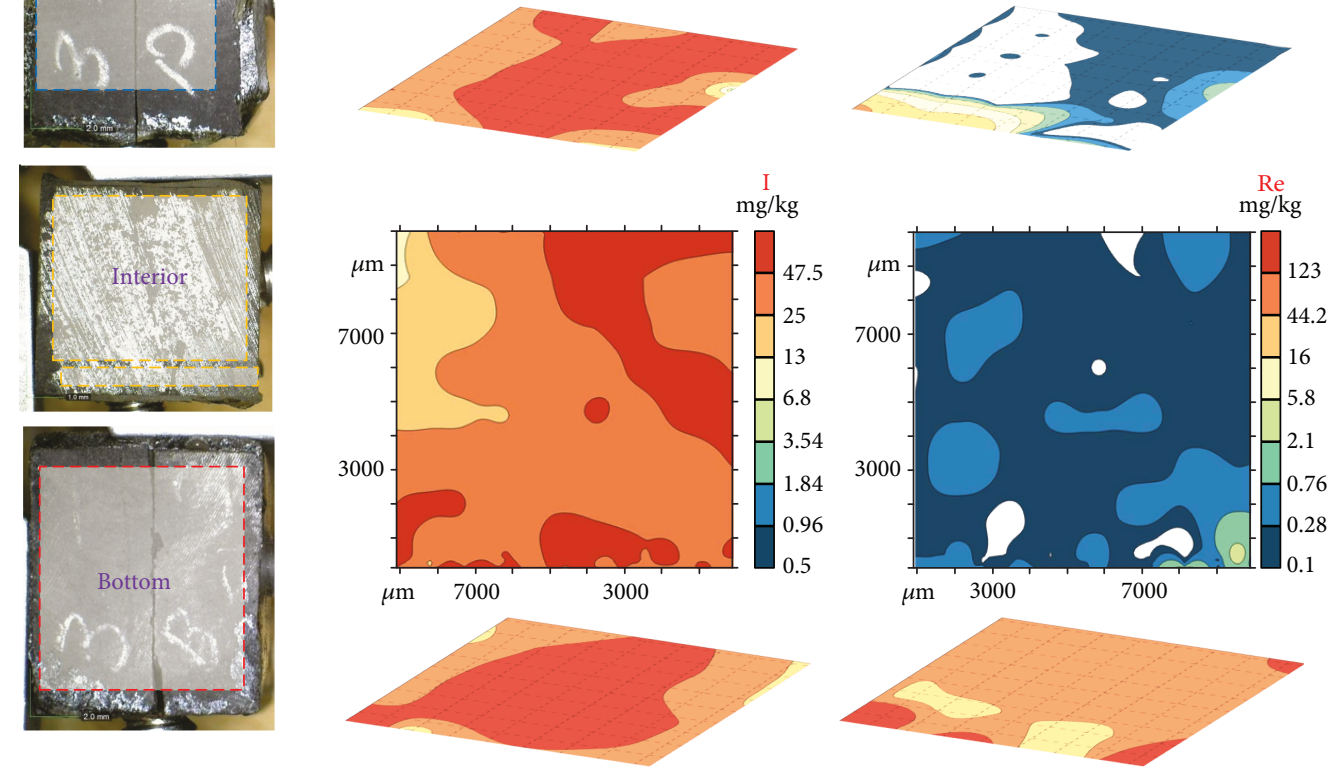

FIGURE 9: Imbibition of organic-I and organic-Re in n-decane into B-13010 sample of Springer shale after the imbibition time of $23.5 \mathrm{hr}$, corresponding to Figure 7c. The interior face is sawed open from the top to the bottom, as shown in the top, interior, and bottom photos. Labeling of 3, B, and P indicates that this is cube number 3, bottom face, and imbibition direction is parallel to the lamination. 
dimensions of organic-Re molecules are $1.27 \mathrm{~nm} \mathrm{~L} \times$ $0.92 \mathrm{~nm} \mathrm{~W} \times 0.78 \mathrm{~nm} \mathrm{H}$, with larger width and height, as well as conformational inflexibility, than organic-I.

\section{Conclusions}

Using multiple and complementary approaches on five core samples from two wells located in the SCOOP, this study examined the pore structure and fluid uptake of Springer shale to better determine pore connectivity and fluid movement which is implicated in low overall recovery in shale reservoirs. Excluding sample B-13047 of silica-dominated lithotype, the Springer shale has an averaged porosity of $6.32 \pm 0.75 \%$ and permeability of $20.0 \pm 6.52 \mathrm{nD}$, with the majority of pore throat diameters ranging at 5-50 $\mathrm{nm}$. Droplet wettability and imbibition methods simulate reservoir conditions and show that the formation has a strong affinity for oil, while possessing a Dalmatian-type wettability characteristic. Utility of multiple tracers of different sizes followed with the mapping of tracer penetration using LA-ICP-MS further illustrates the dual-connectivity behavior of the Springer shale; such test design and the utility of tracers of different molecular sizes in both polar and nonpolar fluids help tease out the intertwined relationship of pore sizes, connectivity, and associated wettability of shale.

There is still much to be learned regarding pore connectivity and fluid uptake (from tracer-containing brine and ndecane and follow-up detection of tracers by LA-ICP-MS) in the Springer shale. More samples need to be analyzed using different and complementary techniques such as gas physisorption isotherm and small-angle neutron scattering, as well as field emission-SEM, focused ion beam-SEM, and nano-CT imaging, to better understand this producing formation and how hydrocarbons migrate through the shale matrix with complex nano-sized pore network.

\section{Nomenclature}

\begin{tabular}{|c|c|}
\hline A: & Pore area $\left(\mathrm{m}^{2} / \mathrm{g}\right)$ \\
\hline$k:$ & Absolute permeability $\left(\mu \mathrm{m}^{2}\right)$ \\
\hline$L_{\mathrm{t}}:$ & $\begin{array}{l}\text { Characteristic (threshold) length (i.e., the } \\
\text { pore-throat diameter corresponding to the } \\
\text { threshold pressure when mercury starts to } \\
\text { span (percolate) the whole sample) }(\mu \mathrm{m})\end{array}$ \\
\hline$L_{\max }:$ & $\begin{array}{l}\text { Pore-throat diameter at which the } \\
\text { hydraulic conductance is maximum }(\mu \mathrm{m})\end{array}$ \\
\hline$\phi:$ & Porosity $(\%)$ \\
\hline$S_{L_{\max }}:$ & Mercury saturation at $L_{\max }(\%)$ \\
\hline$r_{\mathrm{c}}:$ & $\begin{array}{l}\text { Capillary radius related to capillary } \\
\text { pressure }(\mu \mathrm{m})\end{array}$ \\
\hline$r_{\min }:$ & $\begin{array}{l}\text { Minimum detectable capillary radius by } \\
\operatorname{MICP}(\mu \mathrm{m})\end{array}$ \\
\hline$r_{\max }:$ & $\begin{array}{l}\text { Maximum detectable capillary radius by } \\
\operatorname{MICP}(\mu \mathrm{m})\end{array}$ \\
\hline $\mathrm{f}_{\mathrm{V}}(\eta) \mathrm{d} \eta \mathrm{f}_{\mathrm{v}}\left(\mathrm{r}_{\mathrm{c}}\right) \mathrm{dr}_{\mathrm{c}}:$ & $\begin{array}{l}\text { Volume probability density function } \\
\text { (volume of pores with a radius in the } \\
\text { range of } r_{c} \text { to } r_{c}+d_{c} \text { per kg of dry } \\
\text { material) }\left(\mathrm{cm}^{3} / g\right)\end{array}$ \\
\hline$\rho:$ & Skeletal density $\left(\mathrm{g} / \mathrm{cm}^{3}\right)$ \\
\hline
\end{tabular}

$V_{\text {tot }}$ :

$V:$

$V_{t}$

$d:$

$D_{0}:$

$D_{\mathrm{e}}:$

$L:$

$L_{\mathrm{e}}:$

\section{Conflicts of Interest}

The authors declare that there is no conflict of interest regarding the publication of this paper.

\section{Acknowledgments}

Financial assistance for this work is provided by the National Science and Technology Major Project of China (no. 2016ZX05034-002-006), the National Natural Science Foundation of China (no. 41690134), and the Open Funds of State Key Laboratory of Oil and Gas Reservoir Geology and Exploitation at Chengdu University of Technology (no. PLC-201602). The first author thanks Wenxu Hu of Nanjing University in China for the determination of TOC and vitrinite reflectance. The authors greatly appreciate the comments from anonymous reviewers that have improved the quality of this work.

\section{References}

[1] L. L. C. Jefferies, "SCOOP technical overview," in 2014 Jefferies global energy conference, p. 16, Houston, TX, USA, November 2014.

[2] B. J. Cardott, "Oklahoma shale resource play," Oklahoma Geological Society, vol. 2017, pp. 21-30, 2017.

[3] R. D. Andrew, "Springer gas play in western Oklahoma," Oklahoma Geological Survey, OGS SP 2001-1, p. 123, 2001.

[4] C. Welker, S. Feiner, R. Lishansky et al., "Trapped fluid analysis of 58 wells from SCOOP and STACK plays, Oklahoma," in Trapped Fluid Analysis of 58 Wells from the SCOOP and STACK Plays, Oklahoma, San Antonio, Texas, USA, August 2016.

[5] M. Ball, M. Henry, and S. Frezon, "Petroleum geology of the Anadarko Basin region, province (115), Kansas, Oklahoma, and Texas," United States Geological Survey, vol. 19, no. 76, pp. 88-450, 1991.

[6] S. Nash, "The Springer shale: A sleeping giant?," AAPG Search and Discovery, vol. 10664, 2014.

[7] M. Henry and T. Hester, Anadarko Basin Province (058), National Assessment of United States Oil and Gas Resources, 1995. 
[8] T. Jacobs, "Springer shale rising: continental's new niche play," Journal of Petroleum Technology, E\&P Notes, vol. 2014, pp. 36$37,2014$.

[9] Continental Resources, "Investor update," p. 31, 2016, October 2017, http://phx.corporate-ir.net/External.File?t=1\&item $=\mathrm{VH}$ lwZT0yfFBhcmVudElEPTUyMTYyNjN8Q2hpbGRJRD02M TE3MjM=.

[10] M. Menchaca, "Oklahoma oil and gas: Woodford SCOOP wells have stamina," 2014, October 2017, https://info. drillinginfo.com/oklahoma-oil-and-gas-woodford-scoopwells-stamina/.

[11] Q. Hu, R. P. Ewing, and H. D. Rowe, "Low nanopore connectivity limits gas production in Barnett formation," Journal of Geophysical Research: Solid Earth, vol. 120, no. 12, pp. 80738087, 2015.

[12] Q. H. Hu, X. G. Liu, Z. Y. Gao, S. G. Liu, W. Zhou, and W. X. $\mathrm{Hu}$, "Pore structure and tracer migration behavior of typical American and Chinese shales," Petroleum Science, vol. 12, no. 4, pp. 651-663, 2015.

[13] Q. Hu, Y. Zhang, X. Meng, Z. Li, Z. Xie, and M. Li, "Characterization of micro-nano pore networks in shale oil reservoirs of Paleogene Shahejie Formation in Dongying Sag of Bohai Bay Basin, East China," Petroleum Exploration and Development, vol. 44, no. 5, pp. 720-730, 2017.

[14] EDGAR Online, "Eagle Rock Energy partners LP form 425', 2015, October 2017, http://www.barchart.com/plmodules/? module $=$ secFilings $\&$ filingid $=10740545 \&$ type $=$ CONVPDF $\&$ popup $=1$ \&override $=1 \&$ symbol=EROC.

[15] K. Johnson, "Anadarko basin symposium," Oklahoma Geological Society, vol. 90, p. 289, 1988.

[16] J. A. Brewer, R. Good, J. E. Oliver, L. D. Brown, and S. Kaufman, "COCORP profiling across the southern Oklahoma Aulacogen: overthrusting of the Wichita Mountains and compression within the Anadarko basin," Geology, vol. 11, no. 2, pp. 109-114, 1983.

[17] C. Tomlinson and W. McBee, Pennsylvanian Sediments and Orogenies of Ardmore District, vol. 2, no. 19, 1962, Petroleum Geology of Southern Oklahoma, Oklahoma, 1962.

[18] H. Peace, "The Springer group of the Southeastern Anadarko basin in Oklahoma," Shale Shaker, vol. 15, no. 5, pp. 81-99, 1965.

[19] D. T. Boyd, Stratigraphic guide to Oklahoma oil and gas reservoirs, Oklahoma Geological Survey, University of Oklahoma, Norman, OK, USA, 2008.

[20] J. Chrisman, Depositional Setting, Facies, and Petroleum Geology of Boatwright Sandstones (Springer Group) in Parts of Caddo, Canadian, and Blaine Counties, OK, [M.S. thesis], Department of Science, Oklahoma State University, USA, 2009.

[21] A. Rice, Depositional Environment, Petrology, and Compartmentalization of Cunningham and Britt Sandstones in Parts of Caddo, Grady, and Comanche Counties, Anadarko Basin, Oklahoma, [M.S. thesis], Oklahoma State University, 1993.

[22] A. Bennison, "Springer and related rocks of Oklahoma," Tulsa Geological Society Digest, vol. 24, pp. 111-115, 1956.

[23] L. Wilson, Palynological evidence for Mississippian age of the Springer Formation, Ardmore Geological Society, 1966.

[24] R. Hugman and F. Vidas, Oil and Gas Resources of the Mid-Continent Region, Energy and Environmental Analysis. Incorporated, Arlington, VA, 1987.

[25] M. Elias, "Upper Mississippian and lower Pennsylvanian formations of south-central Oklahoma," Petroleum Geology of Southern Oklahoma, vol. 1, no. 16, pp. 56-134, 1951.
[26] P. Smith, H. Walter, and W. Craig, Regional Correlations and Reservoir Characterization Studies of the Springer Group in the Anadarko Basin Area of Western Oklahoma, AAPG Mid-Continent Section Meeting, 1995.

[27] J. Straka, "Conodont evidence of age of Goddard and springer formations, Ardmore Basin, Oklahoma," AAPG Bulletin, vol. 56, 1972.

[28] J. Westheimer, "The Goddard formation, in petroleum geology of southern Oklahoma," in A Symposium Sponsored by the Ardmore Geological Society, vol. 1, pp. 292-396, American Association of Petroleum Geologist, Tulsa, 1954.

[29] R. Blakey, "North America paleogeography maps," 2014, http://cpgeosystems.com/index.html.

[30] P. Huggins, "Fluid uptake of the Goddard Shale Formation in Southeastern Oklahoma, USA," The University of Texas at Arlington, [M.S. thesis], 1995.

[31] R. Laudon, "Chesterian and Morrowan rocks in the McAlester basin of Oklahoma," Oklahoma Geological Survey, vol. 46, 1958.

[32] "DrillingInfo," 2017, http://www.drillinginfo.com.

[33] SY/T 5116-1997, The Determination of Total Organic Carbon in Sedimentary Rock, p. 7, 1997.

[34] SY/T 5124-2012, Method of Determining Microscopically the Reflectance of Vitrinite in Sedimentary Rock, p. 10, 2012.

[35] D. L. Bish and R. C. Reynolds Jr., "Sample preparation for X-ray diffraction," in Modern Powder Diffraction, D. L. Bish and J. E. Post, Eds., pp. 73-99, Reviews in Mineralogy, Volume6 20, Mineralogical Society of America, USA, 1989.

[36] S. Hillier, "Spray drying for X-ray powder diffraction specimen preparation," in International Union of Crystallography Commission on Powder Diffraction, vol. 27, pp. 7-9, Newsletter, 2002.

[37] Z. Gao and Q. Hu, "Estimating permeability using median pore-throat radius obtained from mercury intrusion porosimetry," Journal of Geophysics and Engineering, vol. 10, no. 2, article 025014, 2013.

[38] N. Zhang, M. He, B. Zhang, F. Qiao, H. Sheng, and Q. Hu, "Pore structure characteristics and permeability of deep sedimentary rocks determined by mercury intrusion porosimetry," Journal of Earth Science, vol. 27, no. 4, pp. 670-676, 2016.

[39] E. W. Washburn, "Note on a method of determining the distribution of pore sizes in a porous material," Proceedings of the National Academy of Sciences, vol. 7, no. 4, pp. 115-116, 1921.

[40] S. Wang, F. Javadpour, and Q. Feng, "Confinement correction to mercury intrusion capillary pressure of shale nanopores," Scientific Reports, vol. 6, no. 1, article 20160, 2016.

[41] P. A. Webb, An Introduction to the Physical Characterization of Materials by Mercury Intrusion Porosimetry with Emphasis on Reduction and Presentation of Experimental Data, Micromeritics Instrument Corp, Norcross, Georgia, 2001.

[42] A. J. Katz and A. H. Thompson, "Quantitative prediction of permeability in porous rock," Physical Review B, vol. 34, no. 11, pp. 8179-8181, 1986.

[43] A. J. Katz and A. H. Thompson, "Prediction of rock electrical conductivity from mercury injection measurements," Journal of Geophysical Research, vol. 92, no. B1, pp. 599-607, 1987.

[44] J. Hager, "Steamw drying of porous media," Department of Chemical Engineering, [Ph.D. thesis], Lund University, 1998.

[45] C. W. Crowe, "Methods of lessening the inhibitory effects to fluid flow due to the presence of solid organic substances in a subterranean formation," U.S. Patent Office 3482636, 1969. 
[46] R. Lopez and A. Soria, "Kinematical description of the spontaneous imbibition processes," in IASME/WSEAS International Conference, Athens, Greece, 2007.

[47] B. Chaudhuri, K. Jessen, and T. Tsotsis, Water Inversion in Shale: A Preliminary Study, USC Viterbi Research Symposium, 2010.

[48] S. M. Ma, X. Zhang, N. R. Morrow, and X. Zhou, "Characterization of wettability from spontaneous imbibition measurements," Journal of Canadian Petroleum Technology, vol. 38, no. 13, 1999.

[49] N. R. Morrow and X. Xie, "Oil recovery by spontaneous imbibition from weakly water-wet rocks," Petrophysics, vol. 42, no. $4,2001$.

[50] Z. Gao and Q. Hu, "Wettability of Mississippian Barnett Shale samples at different depths: investigations from directional spontaneous imbibition," AAPG Bulletin, vol. 100, no. 1, pp. 101-114, 2016.

[51] S. E. Buckley and M. C. Leverett, "Mechanism of fluid displacement in sands," Transactions of the AIME, vol. 146, no. 1, pp. 107-116, 1942.

[52] C. C. Mattax and J. R. Kyte, "Imbibition oil recovery from fractured, water-drive reservoir," Society of Petroleum Engineers Journal, vol. 2, no. 2, pp. 177-184, 1962.

[53] M. Q. Hu, P. Persoff, and J. S. Y. Wang, "Laboratory measurement of water imbibition into low-permeability welded tuff," Journal of Hydrology, vol. 242, no. 1-2, pp. 64-78, 2001.

[54] Q. H. Hu, H. Liu, R. Yang et al., "Applying molecular and nanoparticle tracers to study wettability and connectivity of Longmaxi formation in southern China," Journal of Nanoscience and Nanotechnology, vol. 17, no. 9, pp. 62846295, 2017.

[55] Q. Hu, T. J. Kneafsey, J. J. Roberts, L. Tomutsa, and J. S. Y. Wang, "Characterizing unsaturated diffusion in porous tuff gravel," Vadose Zone Journal, vol. 3, no. 4, 2004.

[56] H. E. King, A. P. R. Eberle, C. A. Walters, C. E. Kliewer, D. Ertas, and C. Huynh, "Pore architecture and connectivity in gas shales," Energy and Fuels, vol. 29, no. 3, pp. 13751390, 2015.

[57] Q. Hu and J. S. Y. Wang, "Aqueous-phase diffusion in unsaturated geologic media: a review," Critical Reviews in Environmental Science and Technology, vol. 33, no. 3, pp. 275-297, 2003.

[58] C. J. Gommes, A.-J. Bons, S. Blacher, J. H. Dunsmuir, and A. H. Tsou, "Practical methods for measuring the tortuosity of porous materials from binary or gray-tone tomographic reconstructions," AIChE Journal, vol. 55, no. 8, pp. 20002012, 2009.

[59] R. G. Loucks, R. M. Reed, S. C. Ruppel, and D. M. Jarvie, "Morphology, genesis, and distribution of nanometer-scale pores in siliceous mudstones of the Mississippian Barnett shale," Journal of Sedimentary Research, vol. 79, no. 12, pp. 848-861, 2009.

[60] R. M. Slatt and N. R. O'Brien, "Pore types in the Barnett and Woodford gas shales: contribution to understanding gas storage and migration pathways in fine-grained rocks," AAPG Bulletin, vol. 95, no. 12, pp. 2017-2030, 2011.

[61] C. R. Clarkson, M. Freeman, L. He et al., "Characterization of tight gas reservoir pore structure using USANS/SANS and gas adsorption analysis," Fuel, vol. 95, pp. 371-385, 2012.

[62] M. Mastalerz, A. Schimmelmann, A. Drobniak, and Y. Chen, "Porosity of Devonian and Mississippian New Albany shale across a maturation gradient: insights from organic petrology, gas adsorption, and mercury intrusion," AAPG Bulletin, vol. 97, no. 10, pp. 1621-1643, 2013.

[63] U. Kuila and M. Prasad, "Specific surface area and pore-size distribution in clays and shales," Geophysical Prospecting, vol. 61, no. 2, pp. 341-362, 2013.

[64] K. L. Milliken, M. Rudnicki, D. N. Awwiller, and T. Zhang, "Organic matter-hosted pore system, Marcellus formation (Devonian), Pennsylvania,” AAPG Bulletin, vol. 97, no. 2, pp. 177-200, 2013.

[65] J. Klaver, S. Hemes, M. Houben, G. Desbois, Z. Radi, and J. L. Urai, "The connectivity of pore space in mudstones: insights from high-pressure Wood's metal injection, BIBSEM imaging, and mercury intrusion porosimetry," Geofluids, vol. 15, no. 4, 591 pages, 2015.

[66] R. Yang, S. He, J. Yi, and Q. Hu, "Nano-scale pore structure and fractal dimension of organic-rich Wufeng-Longmaxi shale from Jiaoshiba area, Sichuan Basin: Investigations using FESEM, gas adsorption and helium pycnometry," Marine and Petroleum Geology, vol. 70, pp. 27-45, 2016.

[67] S. C. Löhr, E. T. Baruch, P. A. Hall, and M. J. Kennedy, "Is organic pore development in gas shales influenced by the primary porosity and structure of thermally immature organic matter?," Organic Geochemistry, vol. 87, pp. 119-132, 2015.

[68] M. Pommer and K. Milliken, "Pore types and pore-size distributions across thermal maturity, Eagle Ford formation, southern Texas," AAPG Bulletin, vol. 99, no. 9, pp. 17131744, 2015

[69] J. D. Walls and A. Morcote, "Quantifying variability of reservoir properties from a Wolfcamp formation core," in Unconventional Resources Technology Conference, San Antonio, TX, USA, July 2015.

[70] S. Rezaei Gomari and N. Joseph, "Study of the effect of clay particles on low salinity water injection in sandstone reservoirs," Energies, vol. 10, no. 3, pp. 1-12, 2016.

[71] S. Kiepsch and R. Pelster, "Interplay of vapor adsorption and liquid imbibition in nanoporous Vycor glass," Physical Review E, vol. 93, no. 4, 2016.

[72] O. Vincent, B. Marguet, and A. D. Stroock, "Imbibition triggered by capillary condensation in nanopores," Langmuir, vol. 33, no. 7, pp. 1655-1661, 2017.

[73] Y. Marcus, "Ionic radii in aqueous solutions," Chemical Reviews, vol. 88, no. 8, pp. 1475-1498, 1988.

[74] H. Gamero-Diaz, C. Miller, and R. Lewis, "sCore: a classification scheme for the organic mudstones based on bulk mineralogy," in AAPG Southwest Section Meeting. Search and Discovery Article \#40951, Ft. Worth, Texas, May 2012. 

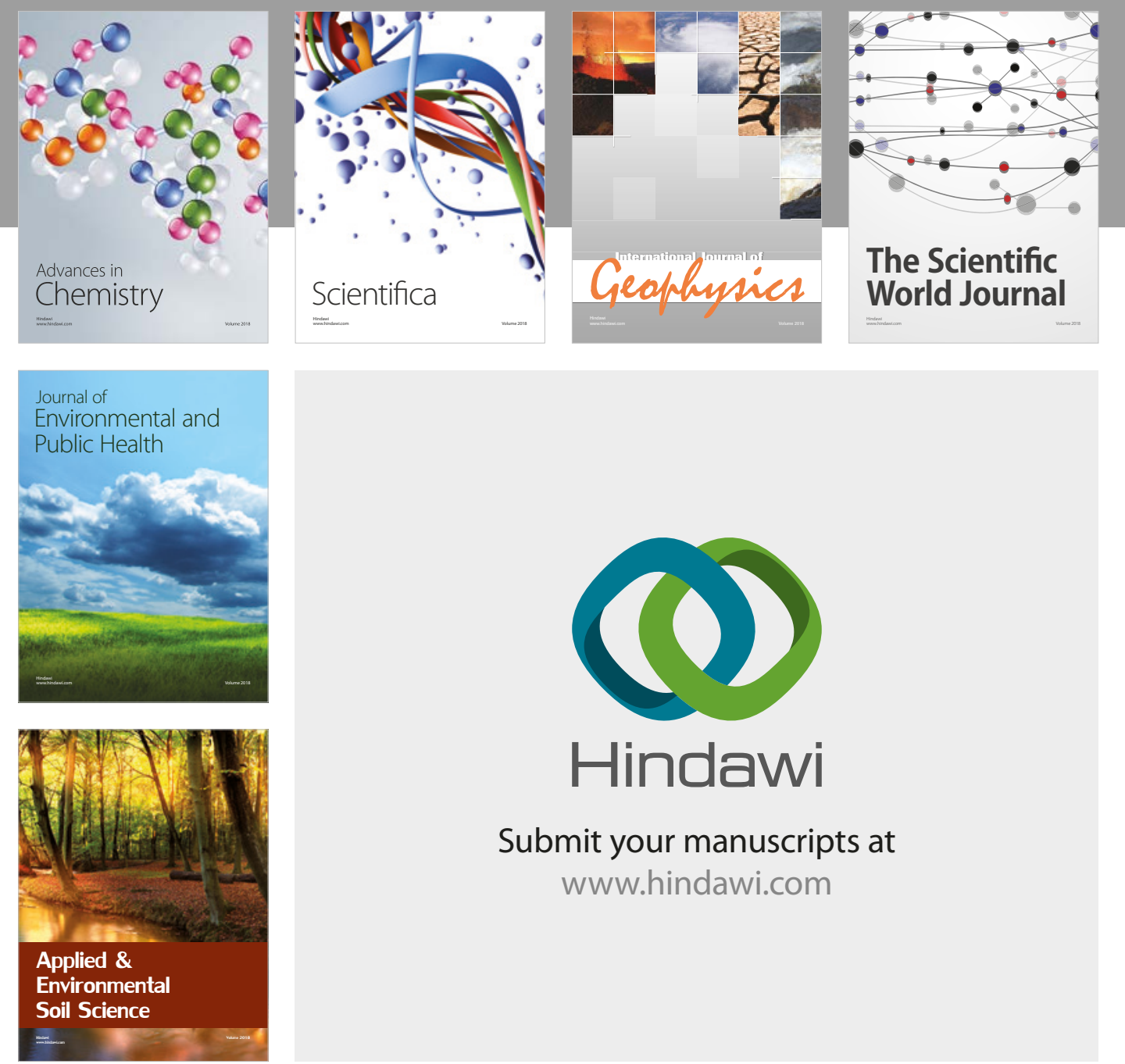

The Scientific

\section{World Journal}
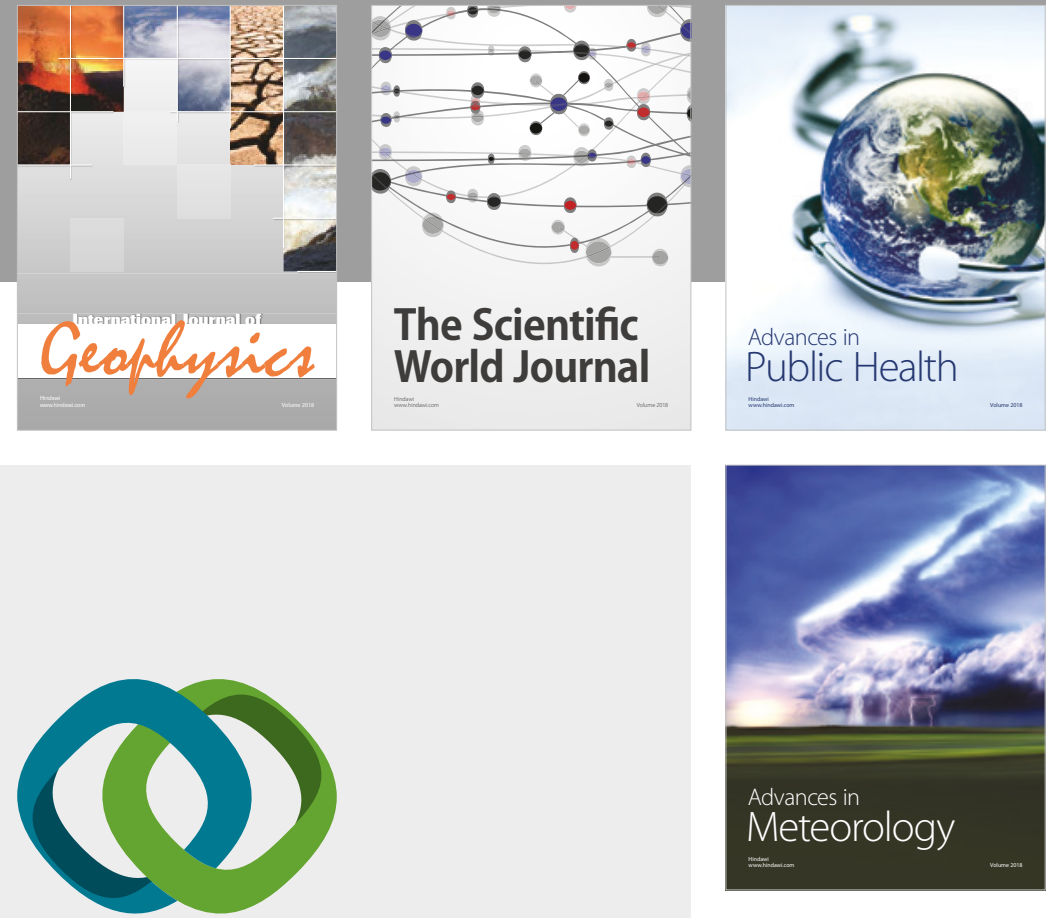

Advan

Public Health

\section{Hindawi}

Submit your manuscripts at

www.hindawi.com
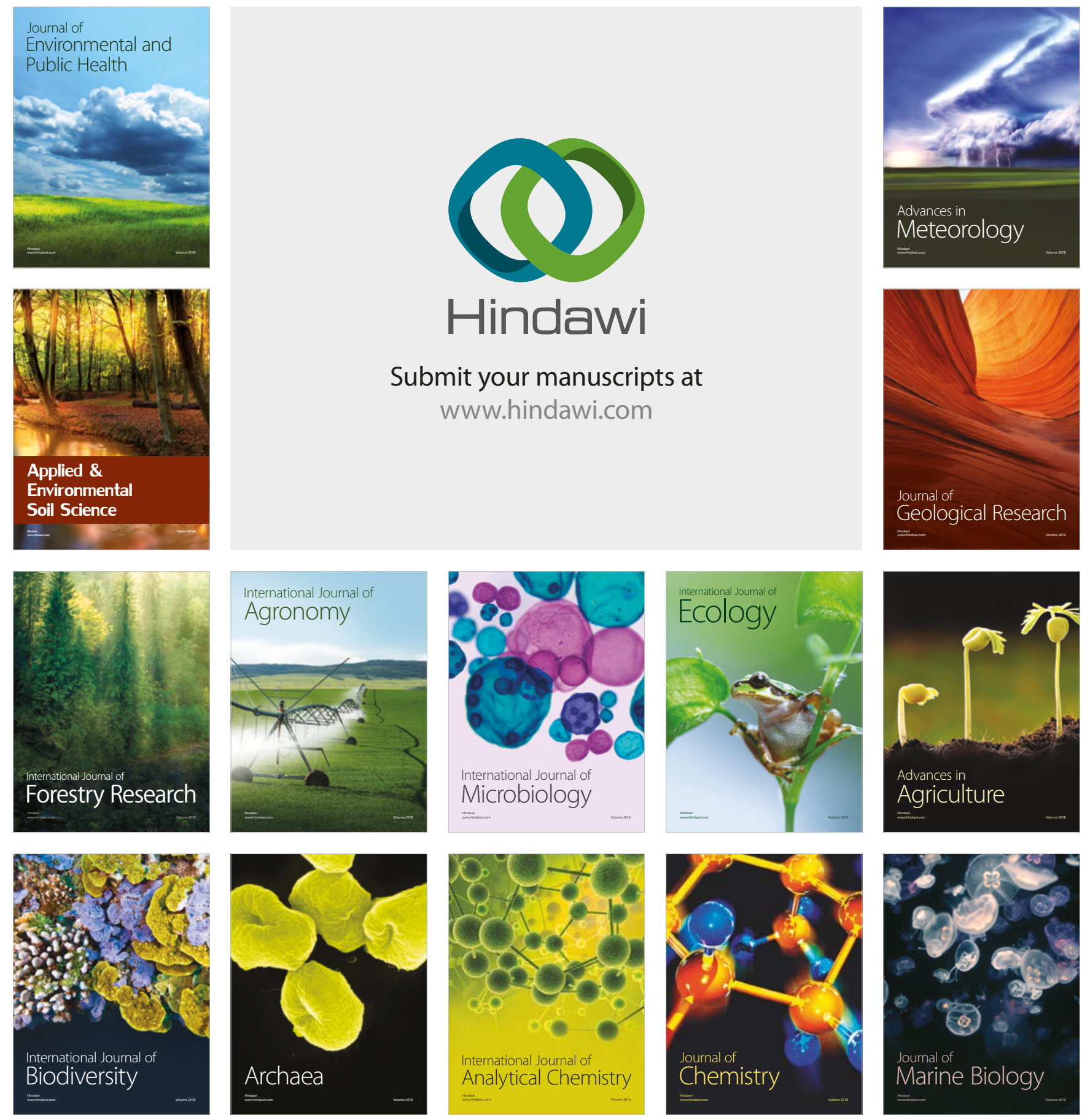